\title{
Carbon Dot/Polymer Composites with Various Precursors and Their Sensing Applications: A Review
}

\author{
Muhammad Zulfajri ${ }^{1, *(D)}$, Sri Sudewi ${ }^{2,3}$, Sri Ismulyati ${ }^{1}$, Akhtar Rasool ${ }^{4}{ }^{(D,}$, Muhammad Adlim ${ }^{5,6}$ \\ and Genin Gary Huang $2,7,8, * \mathbb{D}$
}

1 Department of Chemistry Education, Universitas Serambi Mekkah, Banda Aceh 23245, Indonesia; sri.ismulyati@serambimekkah.ac.id

2 Department of Medicinal and Applied Chemistry, Kaohsiung Medical University, Kaohsiung 80708, Taiwan; u108850005@kmu.edu.tw

3 Department of Pharmacy, Universitas Sam Ratulangi, Manado 95115, Indonesia

4 Department of Environmental Sciences, Osmania University, Hyderabad 500007, Telangana, India; akhtarrasool01@gmail.com

5 Graduate School of Mathematics and Applied Science, Universitas Syiah Kuala, Banda Aceh 23111, Indonesia; adlim@unsyiah.ac.id

6 Chemistry Department, FKIP, Universitas Syiah Kuala, Banda Aceh 23111, Indonesia

7 Department of Medical Research, Kaohsiung Medical University Hospital, Kaohsiung 80708, Taiwan

8 Department of Chemistry, National Sun Yat-sen University, Kaohsiung 80424, Taiwan

* Correspondence: muhammad.zulfajri@serambimekkah.ac.id (M.Z.); genin@kmu.edu.tw (G.G.H.)

Citation: Zulfajri, M.; Sudewi, S.; Ismulyati, S.; Rasool, A.; Adlim, M.; Huang, G.G. Carbon Dot/Polymer Composites with Various Precursors and Their Sensing Applications: A Review. Coatings 2021, 11, 1100. https://doi.org/10.3390/ coatings 11091100

Academic Editor: Je Moon Yun

Received: 26 August 2021

Accepted: 10 September 2021

Published: 12 September 2021

Publisher's Note: MDPI stays neutral with regard to jurisdictional claims in published maps and institutional affiliations.

Copyright: (C) 2021 by the authors. Licensee MDPI, Basel, Switzerland. This article is an open access article distributed under the terms and conditions of the Creative Commons Attribution (CC BY) license (https:/ / creativecommons.org/licenses/by/ $4.0 /)$.
Abstract: Carbon dots (CDs) have generated much interest because of their significant fluorescence (FL) properties, extraordinary photophysical attributes, and long-term colloidal stability. CDs have been regarded as a prospective carbon nanomaterial for various sensing applications because of their low toxicity, strong and broad optical absorption, high chemical stability, rapid transfer properties, and easy modification. To improve their functionality, $\mathrm{CD}$ / polymer composites have been developed by integrating polymers into CDs. CD/polymer composites have diversified because of their easy preparation and applications in sensing, optoelectronics, semiconductors, molecular delivery, and various commercial fields. Many review articles are available regarding the preparation and applications of CDs. Some review articles describing the production and multiple applications of the composites are available. However, no such article has focused on the types of precursors, optical properties, coating characteristics, and specific sensing applications of $\mathrm{CD} /$ polymer composites. This review aimed to highlight and summarize the current progress of $\mathrm{CD} /$ polymer composites in the last five years (2017-2021). First, we overview the precursors used for deriving CDs and CD/polymer composites, synthesis methods for preparing CDs and CD/polymer composites, and the optical properties (absorbance, FL, emission color, and quantum yield) and coating characteristics of the composites. Most carbon and polymer precursors were dominated by synthetic precursors, with citric acid and polyvinyl alcohol widely utilized as carbon and polymer precursors, respectively. Hydrothermal treatment for CDs and interfacial polymerization for CDs/polymers were frequently performed. The optical properties of CDs and CD/polymer composites were almost identical, denoting that the optical characters of CDs were well-maintained in the composites. Then, the chemical, biological, and physical sensing applications of $\mathrm{CD} /$ polymer composites are categorized and discussed. The CD/polymer composites showed good performance as chemical, biological, and physical sensors for numerous targets based on FL quenching efficiency. Finally, remaining challenges and future perspectives for $\mathrm{CD}$ / polymer composites are provided.

Keywords: carbon dots; polymer; composites; synthesis; precursor; optical properties; sensing applications 


\section{Introduction}

In 2004, fluorescent carbon nanomaterials were derived through the purification of SWCNTs by Xu et al. [1]. Then, Sun et al. in 2006 obtained similar fluorescent (FL) carbon NPs, named carbon dots, both dispersed in a solvent and as an extract in a solid state [2]. Subsequently, many studies have been performed to explore CDs in synthesis, characterization, and application aspects. Several names have been proposed for these nanomaterials, including carbon dots (CDs) [2], carbon quantum dots (CQDs) [3], carbon nanodots (CNDs) [4], graphene quantum dots (GQDs) [5], and polymer dots (PDs) [6]. Furthermore, carbonized polymer dots (CPDs), a new kind of CD with polymer/carbon hybrid structure, have begun to garner interest [7]. Although PDs and CPDs are included as types of CD, they have been classified as FL polymers by some researchers. However, the precursors and synthetic methods for PDs/CPDs and CDs are almost identical. CDs have appeared as a novel member of the attractive zero-dimensional carbon nanomaterials and have generated much interest due to their specific physical, chemical, and optical properties [8]. CDs are discrete, quasi-spherical, and clustered domains of many carbon atoms with sizes of $<20 \mathrm{~nm}$ containing carbon skeletons and plentiful surface functional groups [9]. Specifically, the covalent carbon core structure grants CDs excellent stability, while the functional groups on their surface are associated with excellent water solubility and high FL properties $[7,10]$. Generally, the surface functional groups comprise oxygenated groups such as hydroxyls, carboxylic acids, carbonyls, and epoxy groups [11]. CDs have also utilized as a potential green substitute to harmful traditional semiconductor quantum dots because of their biocompatibility [12]. CDs have prominent advantages such as simple and inexpensive synthesis, a wide selection of precursors, good water solubility, high sensitivity and selectivity, tunable surface and fluorescence properties, low toxicity, superior electron transfer ability, high chemical stability, excellent photostability, and cheap scale-up production $[13,14]$. Because their outstanding characteristics, CDs have been widely utilized in biological sensors [15], chemical sensors [16], bioimaging agents [17], optoelectronic devices [18], electrocatalysts [19], energy devices [20], light-emitting devices [21], drug carriers [22], and cancer theragnostic devices [23]. Various carbon precursors have been utilized to produce CDs, including oyster and straw mushrooms [24-26], kumquat [27], kiwi fruit peel [28], turmeric leaf [29], glucose [30], phthalocyanine [31], and p-phenylenediamine [32].

Recently, the incorporation of CDs with various functional molecules/materials to produce composites has aroused increasing research interest. Composites can effectively improve the shortcomings of pure CDs and increase their multipurpose applications. CDs can easily form composites with other materials because of their abundant surface functional groups. To date, CDs composites have been effectively produced with polymers [33], inorganic nanostructures [34,35], and biomaterials [36]. On the other hand, polymers can form as composites with different carbon materials such as fullerene [37], carbon nanofibers [38], carbon nanotubes [39], and graphene-based materials [40]. Unlike other carbon nanomaterials, CDs can incorporate polymers to form the composites with minimum shortcomings and maximum advantages. CDs have been incorporated in polymer matrices, polymeric gel, and molecularly imprinted polymers to form composites [41]. The small size and large number of surface functional groups of CDs allow for strong interaction with polymers, so homogeneous dispersion inside the polymers is possible. These composites have exceptional advantages such as high optical absorptivity, high aqueous solubility, good functionalization, photobleaching resistance, great chemical stability, less toxicity, and high biocompatibility [42]. CD/polymer composites also have improved flexibility, strength, durability, and hydrophobicity [43]. Furthermore, the coating of CDs may offer polymers with some desired abilities, such as self-healing, enhanced mechanical performance, shape memory, anticorrosion, stimuli-responsive, and electrochemical characteristics [9]. CD/polymer composites have potential applications in various fields such as anticounterfeit [44], UV shields [45], optoelectronic devices [18], solar cells [46], supercapacitors [47], solid-state optical films [48], catalyst [49], and sensors [50]. 
Recently, much progress has been made in the preparation, characterization, and application of $\mathrm{CD} /$ polymer composites. With different aims and perspectives, several review articles on the $C D /$ polymer composites are available $[9,11,12,33,41,49,51-53]$. Most articles to date have discussed the preparation, physicochemical properties, and various applications of $\mathrm{CD} /$ polymer composites. However, no article has yet focused on the precursors, optical properties, coating characteristics, and specific sensing applications of $\mathrm{CD} /$ polymer composites. This review article was provided to complete the aforementioned gaps. This review is important to understand the recent progress of $\mathrm{CD} /$ polymer composites with some essential aspects. The essential aspects related to the precursors, synthesis methods, optical properties, coating characters, and sensing applications of $\mathrm{CD} /$ polymer composites are highlighted. Unlike in other reviews, both carbon and polymer precursors are tabulated. The representative precursors for preparing $\mathrm{CD} /$ polymer composites and the synthesis methods for $\mathrm{CD}$ /polymer composites are illustrated in Figure 1. We focus only on those synthesis methods for CDs that were utilized before preparing $\mathrm{CD}$ /polymer composites. The optical properties of $\mathrm{CD} /$ polymer composites are discussed, and some physicochemical and coating characteristics affecting the optical properties are also provided. Then, we specifically divided the sensing applications of $\mathrm{CD}$ /polymer composites into three sensing categories: chemical, biological, and physical sensors. Finally, some remaining challenges and future perspectives for $\mathrm{CD} /$ polymer composites are provided to improve their functionality, such as exploring new green and cheap precursors, the one-step synthesis method, the heteroatom-doping effect, and new sensing methods.
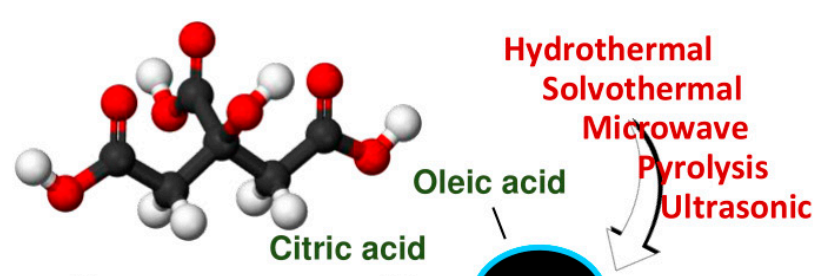

Precursors

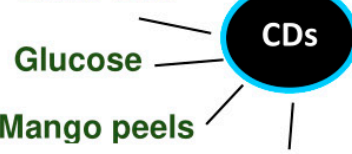

Rosemary leaves

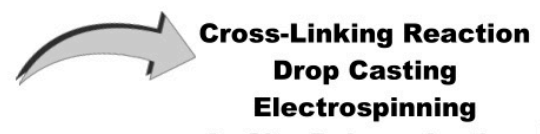

In Situ Polymerization Interfacial Polymerization Reverse Microemulsion Polymerization Sol-Gel

Schiff Base Reaction Thermal Treatment
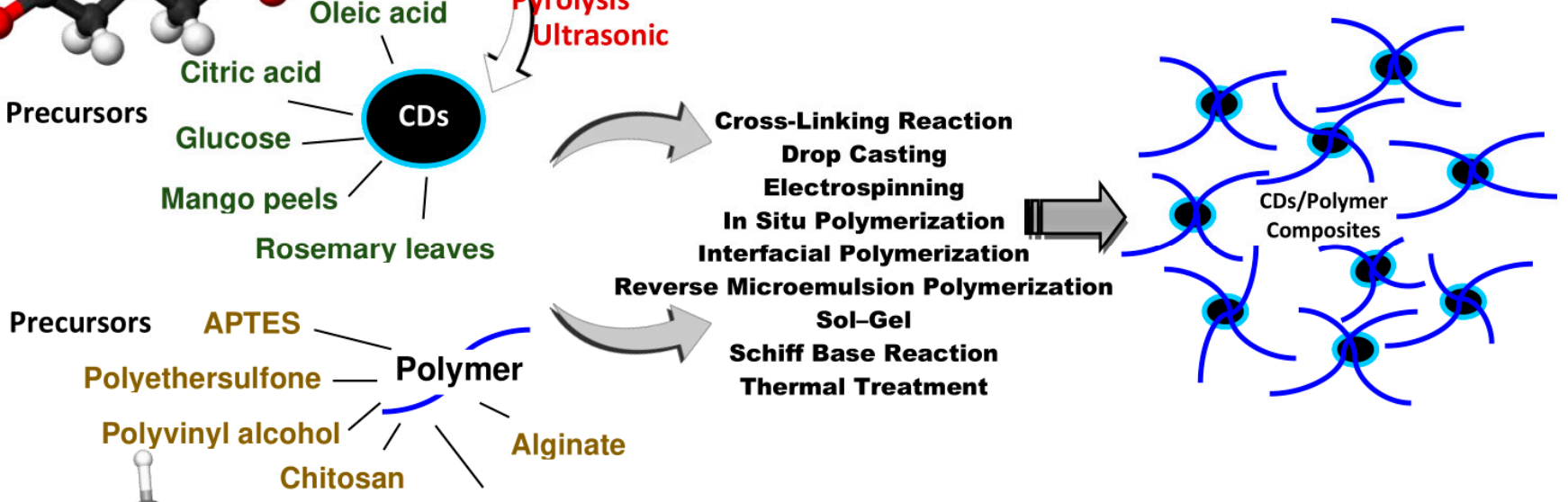

Polydopamine

Figure 1. CD precursors, polymer precursors, and preparation methods for CD/polymer composites. The chemical structures of citric acid and polyvinyl alcohol, as the most used precursors for $\mathrm{CD}$ /polymer composites, are included.

\section{Precursors for CD/Polymer Composites}

The carbon precursors for the production of CDs can be either natural or manmade/synthetic products. Natural resources have various merits as precursors to prepare CDs compared to synthetic products, such as low-cost and substantial abundance in surroundings [54]. Additionally, CD preparation from natural precursors can transform low-value natural/biological waste into meaningful and functional materials. Natural precursors that have heteroatoms such as nitrogen $(\mathrm{N})$, sulfur $(\mathrm{S})$, phosphorus $(\mathrm{P})$, and boron (B) are very comfortable starting materials with which to prepare doped CDs, unlike other doped CDs derived from synthetic precursors, which require the external addition of 
heteroatom-containing compounds [55]. Several natural products have been used for the preparation of CDs before manufacturing their composites with polymers, including inner cassava peels [56], Acerola fruit [57], mango peels [58], Cedrus [59], rosemary leaves [60], chitosan [61], and starch [62]. Although CDs from natural products have various prominent advantages, as mentioned above, they usually need more time for pretreatment and have low quantum yields (QYs) compared to those derived from synthetic products. Some synthetic products have also been used to prepare CDs before incorporating them with polymers, such as citric acid [63], glucose [64], oleic acid [65], ethanolamine [66], and several others.

Furthermore, several polymer precursors have been utilized to prepare $\mathrm{CD}$ /polymer composites, including natural precursors such as chitosan [67], cellulose acetate [65], and alginate [68] and synthetic precursors such as APTES [69], polyethersulfone [70], polyethyleneimine [71], polydopamine [72], polystyrene [73], polyvinyl alcohol [74], and many others. Some of these are functional monomers used to produce polymers during the polymerization process with CDs. As shown in Table 1, most CDs and polymer precursors in the literature were synthetic/manmade precursors rather than natural carbon and polymer precursors. Citric acid and polyvinyl alcohol have often been utilized as carbon and polymer precursors, respectively. Although synthetic carbon and polymer precursors are more expensive than natural precursors, scientists have widely used them to prepare $\mathrm{CD} /$ polymer composites. The reason for this may be that synthetic precursors contain specific ingredients, while natural precursors have complex ingredients and require pretreatment before the synthesis of $\mathrm{CDs}$ and $\mathrm{CD}$ /polymer composites. Furthermore, synthetic precursors, compared to natural precursors, provide easy designability, adjustability, and compositional control through their synthesis procedures. The structure and composition of the composites can thereby be simply controlled, especially with some controlled radical polymerizations. However, natural precursors have been suggested for producing ecofriendly nanomaterials with inexpensive preparation. In addition, as presented in Table 1, some nitrogen dopants were reacted with carbon precursors to obtain $\mathrm{N}$-doped $\mathrm{CDs}$ such as urea, ethylenediamine (ED), $\mathrm{NH}_{3}$, cysteine, octadecylamine (ODA), carbamide, polyethyleneimine (PEI), 2-aminothiophenol (2-AT), and p-phenylenediamine (PPD). The nitrogen dopants were used to enhance the fluorescence properties of the CDs with high QYs.

Table 1. Several precursors for the preparation of $\mathrm{CD} /$ polymer composites.

\begin{tabular}{|c|c|c|c|c|c|}
\hline Composite Name & CDs Precursor & Type & Polymer Precursor & Type & Ref. \\
\hline CDs@MIPs & Citric acid & $\mathrm{s}$ & $\begin{array}{l}\text { (3-aminopropyl) } \\
\text { triethoxysilane }\end{array}$ & $\mathrm{s}$ & [63] \\
\hline CDs@MIPs & Citric acid & S & $\begin{array}{l}\text { (3-aminopropyl) } \\
\text { triethoxysilane }\end{array}$ & S & [69] \\
\hline MCOFs@MIPs@CDs & Citric acid & $S$ & $\begin{array}{l}\text { (3-aminopropyl) } \\
\text { triethoxysilane }\end{array}$ & $\mathrm{s}$ & [75] \\
\hline $\mathrm{CDs} / \mathrm{Fe}_{3} \mathrm{O}_{4} @ \mathrm{MIPs}$ & Citric acid & $\mathrm{s}$ & $\begin{array}{l}\text { (3-aminopropyl) } \\
\text { triethoxysilane }\end{array}$ & $\mathrm{S}$ & [76] \\
\hline PES/CDs & Citric acid & $\mathrm{S}$ & Polyethersulfone & $\mathrm{S}$ & [70] \\
\hline TFN-(Na-CQDs) & Citric acid & $\mathrm{S}$ & Polyethersulfone & $\mathrm{S}$ & [77] \\
\hline Na-CQD-TFN & Citric acid & $\mathrm{S}$ & Polyethersulfone & $\mathrm{S}$ & [78] \\
\hline TFC(Na-CQDs) & Citric acid & $\mathrm{s}$ & Polyethersulfone & $\mathrm{s}$ & [79] \\
\hline GQD-TFN membrane & Citric acid & $\mathrm{s}$ & Polyethersulfone & $\mathrm{s}$ & [80] \\
\hline PAN/PEI-CDs & Citric acid & $\mathrm{S}$ & Polyethyleneimine & $\mathrm{S}$ & [71] \\
\hline PEI/GQDs-TFC & Citric acid & $\mathrm{s}$ & Polyethyleneimine & $\mathrm{s}$ & [81] \\
\hline TFN-CQD membrane & Citric acid & $\mathrm{s}$ & Polysulfone & $\mathrm{s}$ & [82] \\
\hline AC-dots-DNT-MIPs & Citric acid & $\mathrm{S}$ & Methyl acrylate & $\mathrm{S}$ & [83] \\
\hline GQDs-TFN SRNF & Citric acid & $\mathrm{s}$ & $\begin{array}{l}\text { Polyimide } \\
\text { Pold }\end{array}$ & $\mathrm{S}$ & [84] \\
\hline TFC-PES-PDA-CQD & Citric acid & $\mathrm{s}$ & Polydopamine & $\mathrm{s}$ & [72] \\
\hline GQDs/PVDF & Citric acid & $\mathrm{s}$ & Polyvinylidene fluoride & $\mathrm{s}$ & [85] \\
\hline
\end{tabular}


Table 1. Cont.

\begin{tabular}{|c|c|c|c|c|c|}
\hline Composite Name & CDs Precursor & Type & Polymer Precursor & Type & Ref. \\
\hline GQDs/PIP-TMC TFN & Citric acid & S & $\begin{array}{l}\text { Piperazine/trymesoyl } \\
\text { chloride }\end{array}$ & S & [86] \\
\hline PES/GQDs-TMC & Citric acid & $S$ & Trymesoyl chloride & $S$ & [87] \\
\hline C-MIP & Citric acid, Urea & $S$ & Acrylamide & $S$ & [88] \\
\hline CD/PVA films & Citric acid, Urea & $S$ & Polyvinyl alcohol & S & [89] \\
\hline WCDs@PS & Citric acid, Urea & $S$ & Polystyrene & $S$ & [73] \\
\hline PPy@Cdots & Citric acid, Urea & $\mathrm{S}$ & Pyrrole & $S$ & [90] \\
\hline PANI@Cdots & Citric acid, ED & $S$ & Aniline & S & [90] \\
\hline CDs@PVA & Citric acid, $\mathrm{NH}_{3}$ & $S$ & Polyvinyl alcohol & S & [91] \\
\hline HMIP@CDs & $\begin{array}{l}\text { Ammonium citrate, } \\
\text { Cysteine }\end{array}$ & S & Styrene & $S$ & [92] \\
\hline $\mathrm{C}_{18}$-CQD membrane & Citric acid, ODA & $S$ & Tolylene-2,4-diisocyanate & $S$ & [93] \\
\hline CDs/PNVCL@MSNs & Citric acid, carbamide & $S$ & Poly(N-vinylcaprolactam) & S & [94] \\
\hline CS/PVA/CDs & Citric acid, PEI & S & Chitosan, Polyvinyl alcohol & $\mathrm{N}, \mathrm{S}$ & [95] \\
\hline TPU/CDs & Citric acid, 2AT & $S$ & Poly(tetramethylene glycol) & S & [96] \\
\hline BMIP@CDs & Glucose & $S$ & Dopamine & $S$ & [64] \\
\hline CD-TFN membrane & Glucose & $S$ & Polysulfone & $S$ & [97] \\
\hline PDA-CQDs & Glucose & $S$ & Polydopamine & $S$ & [98] \\
\hline Poly(VPBA-AAm)-CDs & Glucose & $S$ & $\begin{array}{c}\text { 4-vinylphenylboronic acid, } \\
\text { Acrylamide }\end{array}$ & $\mathrm{S}$ & [99] \\
\hline CDs-PEI/PES & Glucose & S & Polyethyleneimine & S & [100] \\
\hline PVA-N@C-dots & PEG -400 & $S$ & Polyvinyl alcohol & $S$ & [74] \\
\hline $\mathrm{y}-\mathrm{CD} / \mathrm{PVA}$ & o-phenylenediamine & $S$ & Polyvinyl alcohol & S & [67] \\
\hline CD/PVA films & Urea, PPD & $S$ & Polyvinyl alcohol & $S$ & [101] \\
\hline $\mathrm{PVA} / \mathrm{CDs}$ & $\begin{array}{c}\text { Carboxymethylcellulose, } \\
\text { PEI }\end{array}$ & $\mathrm{N}, \mathrm{S}$ & Polyvinyl alcohol & $S$ & [102] \\
\hline PVA/CD films & Inner cassava peels & $\mathrm{N}$ & Polyvinyl alcohol & $S$ & [56] \\
\hline C-dots/PVA & Acerola fruit & $\mathrm{N}$ & Polyvinyl alcohol & S & [57] \\
\hline CQDs@MIPs & Mango peels & $\mathrm{N}$ & $\begin{array}{l}\text { (3-aminopropyl) } \\
\text { triethoxysilane }\end{array}$ & $S$ & [58] \\
\hline MIPs-GSCDs & Cedrus & $\mathrm{N}$ & $\begin{array}{l}\text { (3-aminopropyl) } \\
\text { triethoxysilane }\end{array}$ & $S$ & [59] \\
\hline $\mathrm{CDs@SiO}{ }_{2} @ \mathrm{MIPs}$ & Rosemary leaves & $\mathrm{N}$ & $\begin{array}{l}\text { (3-aminopropyl) } \\
\text { triethoxysilane }\end{array}$ & $\mathrm{S}$ & [60] \\
\hline PAN/CQD nanofibers & Chitosan & $\mathrm{N}$ & Polyacrylonitrile & $S$ & [61] \\
\hline CD-MIPGlcA & Starch, Tryptophan & $\mathrm{N}, \mathrm{S}$ & $\mathrm{AB}^{1}$, methacrylamide & $S$ & [62] \\
\hline y-CDs/CS & o-phenylenediamine & $\mathrm{S}$ & Chitosan & $\mathrm{N}$ & [67] \\
\hline CDs-polymer & Oleic acid & $S$ & Cellulose acetate & $\mathrm{N}$ & [65] \\
\hline CDs@Cu/Alg & $\begin{array}{l}\text { Cetylpyridinium } \\
\text { chloride }\end{array}$ & $S$ & Alginate & $\mathrm{N}$ & [68] \\
\hline C-dot/PEI gel & Aldehyde & $S$ & Polyethyleneimine & $S$ & [103] \\
\hline CDs-polymer & Hexamethylenetetramine & $S$ & Polycarbonate & $S$ & [104] \\
\hline $\mathrm{PE} / \mathrm{CDs}$ & Ethanolamine & $S$ & Polyethylene & S & [66] \\
\hline $\mathrm{PP} / \mathrm{CDs}$ & Ethanolamine & $\mathrm{S}$ & Polypropylene & $S$ & [66] \\
\hline PEG/CDs & Ethanolamine & $S$ & Polyethylene glycol & $S$ & [66] \\
\hline CDs/clay/NIPAm & $\beta$-cyclodextrin & $S$ & N-isopropylacrylamide & $S$ & [105] \\
\hline C-dot/PVB film & $\begin{array}{l}\text { Cetylpyridinium } \\
\text { chloride/Daaq }\end{array}$ & S & $\begin{array}{c}\text { Polyvinyl butyral, Polyvinyl } \\
\text { alcohol }\end{array}$ & S & [50] \\
\hline aGQDs-TFN OSN & Graphene oxide & $S$ & Polyimide & $S$ & [106] \\
\hline
\end{tabular}

Abbreviations: $\mathrm{S}=$ synthetic, $\mathrm{N}=$ natural, $\mathrm{AB}=(4$-Acrylamidophenyl) (amino)methaniminium acetate, Daaq = 1,5-diamoanthraquinone.

\section{Synthesis Methods for CD/Polymer Composites}

CD preparation can be carried out through top-down and bottom-up synthesis methods. The top-down approaches are defined by the destruction of bigger carbon materials by physical/chemical means such as laser ablation, electrochemical oxidation, chemical oxidation, arc discharge, and ultrasonic treatment [107]. In contrast, the bottom-up approaches are defined by the conversion of small carbon molecules into CDs via a chemical reaction 
such as solvothermal treatment, hydrothermal treatment, microwave treatment, pyrolysis, plasma treatment, or the template route. To prepare CDs before incorporating them with polymers, hydrothermal, solvothermal, microwave, pyrolysis, and ultrasonic treatments have been used. Meanwhile, $\mathrm{CD} /$ polymer composites have been prepared using several techniques including stirring, sol-gel, drop casting, conventional solution casting, in situ chemical polymerization, reverse microemulsion polymerization, interfacial polymerization, cross-linking reaction, photopolymerization, polymer-assisted self-assembly, Schiff base reaction, bulk polymerization, electrospinning, thermal treatment, hydrothermal treatment, nonsolvent induced phase inversion, and free radical dispersion polymerization. The hydrothermal treatment has been most utilized for the preparation of CDs for composites according to our overview of the available literature. Composite names and the features of synthesis methods for CDs and CD/polymer composites can be seen in Table 2. This section overviews the synthesis methods mentioned above for producing $\mathrm{CD} /$ polymer composites.

Table 2. Synthesis methods for CDs and CD/polymer composites.

\begin{tabular}{|c|c|c|c|c|}
\hline \multirow{2}{*}{ Composite Name } & \multicolumn{3}{|c|}{ Synthesis Methods } & \multirow{2}{*}{ Ref. } \\
\hline & CDs & Temp/Heat, Time & CD/Polymer Composites & \\
\hline $\mathrm{PVA} / \mathrm{CDs}$ & Hydrothermal & $260^{\circ} \mathrm{C}, 2 \mathrm{~h}$ & Stirring & [102] \\
\hline CDs@MIPs & Hydrothermal & $200^{\circ} \mathrm{C}, 2 \mathrm{~h}$ & Sol-Gel & [63] \\
\hline CDs@MIPs & Hydrothermal & $210^{\circ} \mathrm{C}, 5 \mathrm{~h}$ & Sol-Gel & [69] \\
\hline BMIP@CDs & Hydrothermal & $90{ }^{\circ} \mathrm{C}, 0.5 \mathrm{~h}$ & Sol-Gel & [64] \\
\hline CQDs@MIPs & Hydrothermal & $200{ }^{\circ} \mathrm{C}, 4 \mathrm{~h}$ & Sol-Gel Hydrolysis & [58] \\
\hline Y-CD/PVA, Y-CD/CS & Hydrothermal & $130^{\circ} \mathrm{C}, 2 \mathrm{~h}$ & Drop casting & [67] \\
\hline C-dots/PVA & Hydrothermal & $160{ }^{\circ} \mathrm{C}, 18 \mathrm{~h}$ & Conventional solution casting & [57] \\
\hline PPy@Cdots/PANI@Cdots & Hydrothermal & $230^{\circ} \mathrm{C}, 4 \mathrm{~h}$ & In situ chemical polymerization & [90] \\
\hline MCOFs@MIPs@CDs & Hydrothermal & $200{ }^{\circ} \mathrm{C}, 2 \mathrm{~h}$ & $\begin{array}{c}\text { Reverse microemulsion } \\
\text { polymerization }\end{array}$ & [75] \\
\hline MIPs-GSCDs & Hydrothermal & $180^{\circ} \mathrm{C}, 12 \mathrm{~h}$ & $\begin{array}{l}\text { Reverse microemulsion } \\
\text { polymerization }\end{array}$ & [59] \\
\hline 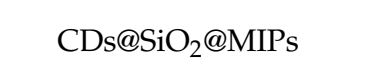 & Hydrothermal & $180^{\circ} \mathrm{C}, 12 \mathrm{~h}$ & $\begin{array}{l}\text { Reverse microemulsion } \\
\text { polymerization }\end{array}$ & [60] \\
\hline aGQDs-TFN OSN & Hydrothermal & $120^{\circ} \mathrm{C}, 5 \mathrm{~h}$ & Interfacial polymerization & [106] \\
\hline PDA-CQDs & Hydrothermal & $180^{\circ} \mathrm{C}, 20 \mathrm{~h}$ & Interfacial polymerization & [98] \\
\hline CD-TFN membrane & Hydrothermal & $200^{\circ} \mathrm{C}, 12 \mathrm{~h}$ & Interfacial polymerization & [97] \\
\hline TFC(Na-CQDs) & Hydrothermal & $180^{\circ} \mathrm{C}, 3 \mathrm{~h}$ & Interfacial polymerization & [79] \\
\hline PEI/CDs/PES & Hydrothermal & $180^{\circ} \mathrm{C}, 20 \mathrm{~h}$ & Cross-linking & [100] \\
\hline CDs/clay/NIPAm & Hydrothermal & $70^{\circ} \mathrm{C}, 4 \mathrm{~h}$ & In situ polymerization & [105] \\
\hline TPU/CDs & Hydrothermal & $170^{\circ} \mathrm{C}, 3 \mathrm{~h}$ & In situ polymerization & [96] \\
\hline CDs-polymer & Hydrothermal & $150^{\circ} \mathrm{C}, 12 \mathrm{~h}$ & Hydrothermal & [104] \\
\hline CD-MIPGlcA & Hydrothermal & $160^{\circ} \mathrm{C}, 12 \mathrm{~h}$ & Photopolymerization & [62] \\
\hline WCDs@PS & Solvothermal & $180^{\circ} \mathrm{C}, 6 \mathrm{~h}$ & Polymer-assisted self-assembly & [73] \\
\hline CD/PVA films & Solvothermal & $120,150,180{ }^{\circ} \mathrm{C}, 6 \mathrm{~h}$ & Stirring & [89] \\
\hline $\mathrm{CDs} / \mathrm{Fe}_{3} \mathrm{O}_{4} @ \mathrm{MIPs}$ & Solvothermal & $240^{\circ} \mathrm{C}, 2 \mathrm{~h}$ & $\begin{array}{l}\text { Reverse microemulsion } \\
\text { polymerization }\end{array}$ & [76] \\
\hline C-MIP & Solvothermal & $180^{\circ} \mathrm{C}, 4 \mathrm{~h}$ & $\begin{array}{l}\text { Reverse microemulsion } \\
\text { polymerization }\end{array}$ & [88] \\
\hline C-dot/PEI gel & Solvothermal & $150^{\circ} \mathrm{C}, 2 \mathrm{~h}$ & Schiff base reaction & [103] \\
\hline AC-dots-DNT-MIPs & Solvothermal & $170^{\circ} \mathrm{C}, 2 \mathrm{~h}$ & Stirring/Bulk polymerization & [83] \\
\hline PAN/CQD nanofibers & Solvothermal & $180^{\circ} \mathrm{C}, 16 \mathrm{~h}$ & Electrospinning & {$[61]$} \\
\hline C-dot/PVB film & $\begin{array}{l}\mathrm{NaOH} \text { reac- } \\
\text { tion/Solvothermal }\end{array}$ & $\underset{\mathrm{h}}{25^{\circ} \mathrm{C}, 12 \mathrm{~h} / 200{ }^{\circ} \mathrm{C}, 24}$ & Stirring & [50] \\
\hline CDs/PNVCL@MSNs & Microwave & $3 \mathrm{~min}$ & Stirring & [94] \\
\hline
\end{tabular}


Table 2. Cont.

\begin{tabular}{|c|c|c|c|c|}
\hline \multirow{2}{*}{ Composite Name } & \multicolumn{3}{|c|}{ Synthesis Methods } & \multirow{2}{*}{ Ref } \\
\hline & CDs & Temp/Heat, Time & CD/Polymer Composites & \\
\hline CDs@PVA & Microwave & $650 \mathrm{~W}, 6 \mathrm{~min}$ & Thermal treatment & [91] \\
\hline HMIP@CDs & Microwave & $750 \mathrm{~W}, 2.5 \mathrm{~min}$ & Sol-Gel & [92] \\
\hline PAN/PEI-CDs & Microwave & $750 \mathrm{~W}, 5 \mathrm{~min}$ & Interfacial polymerization & [71] \\
\hline CDs-PET film & Microwave & $850 \mathrm{~W}, 5 \mathrm{~min}$ & Drop casting & [108] \\
\hline PES/CDs & Pyrolysis & $160^{\circ} \mathrm{C}, 55 \mathrm{~min}$ & Nonsolvent Induced phase inversion & [70] \\
\hline $\begin{array}{c}\text { PE/CDs, PP/CDs, } \\
\text { PEG/CDs }\end{array}$ & Pyrolysis & $160,180^{\circ} \mathrm{C}, 60 \mathrm{~min}$ & Thermal treatment & [66] \\
\hline CDs-polymer & Pyrolysis & $230-260{ }^{\circ} \mathrm{C}$, a few $\min$ & Magnetic stirring & [65] \\
\hline GQDs-TFN SRNF & Pyrolysis & $200^{\circ} \mathrm{C}, 30 \mathrm{~min}$ & Interfacial polymerization & {$[84]$} \\
\hline $\mathrm{C}_{18}$-CQDs membrane & Pyrolysis & $200^{\circ} \mathrm{C}, 4 \mathrm{~h}$ & Cross-linking reaction & {$[93]$} \\
\hline TFN-(Na-CQDs) & Pyrolysis & $180^{\circ} \mathrm{C}, 3 \mathrm{~h}$ & Interfacial polymerization & {$[77]$} \\
\hline PEI/GQDs-TFC & Pyrolysis & $200^{\circ} \mathrm{C}, 30 \mathrm{~min}$ & Interfacial polymerization & [81] \\
\hline TFN-CQD membrane & Pyrolysis & $200^{\circ} \mathrm{C}, 2 \mathrm{~h}$ & Interfacial polymerization & {$[82]$} \\
\hline GQD-TFN membrane & Pyrolysis & $200^{\circ} \mathrm{C}, 30 \mathrm{~min}$ & Interfacial polymerization & [80] \\
\hline Na-CQD-TFN & Pyrolysis & $180^{\circ} \mathrm{C}, 3 \mathrm{~h}$ & Interfacial polymerization & [78] \\
\hline GQDs/PIP-TMC TFN & Pyrolysis & $200^{\circ} \mathrm{C}, 15 \mathrm{~min}$ & Interfacial polymerization & [86] \\
\hline TFC-PES-PDA-CQD & Pyrolysis & $180^{\circ} \mathrm{C}, 3 \mathrm{~h}$ & Interfacial polymerization & {$[72]$} \\
\hline PES/GQDs-TMC & Pyrolysis & $200^{\circ} \mathrm{C}, 15 \mathrm{~min}$ & Interfacial polymerization/thermal & {$[87]$} \\
\hline GQDs/PVDF & Pyrolysis & $200^{\circ} \mathrm{C}, 30 \mathrm{~min}$ & Electrospinning & {$[85]$} \\
\hline CDS@Cu/Alg & Ultrasonic & $25^{\circ} \mathrm{C}, 30 \mathrm{~min}$ & Cross-linking & {$[68]$} \\
\hline PVA-N@C-dots & Ultrasonic & $60{ }^{\circ} \mathrm{C}, 3 \mathrm{~h}$ & Stirring/drop-cast & {$[74]$} \\
\hline Poly(VPBA-AAm)-CDs & $\begin{array}{l}\text { Ultrasonic and } \\
\text { hydrothermal }\end{array}$ & $8 \mathrm{~h} / 200^{\circ} \mathrm{C}, 24 \mathrm{~h}$ & $\begin{array}{l}\text { Free radical dispersion } \\
\text { polymerization }\end{array}$ & [99] \\
\hline
\end{tabular}

\subsection{Hydrothermal Treatment}

Hydrothermal treatment is a low-cost, secure, and environmentally friendly method for the preparation of CDs. In a typical procedure, a precursor mixed in pure water is inserted in a Teflon-lined autoclave and heated at $70-260{ }^{\circ} \mathrm{C}$ for $0.5-24 \mathrm{~h}$ in a heating oven [109]. The color of the solution alters to a yellow or brown, denoting the CDs' formation. Subsequently, separation and purification are performed to obtain pure CDs. The preparation process can avoid multistep passivation, expensive reagents, and sophisticated instruments [110]. Although this method is cheap, environmentally friendly, safe, and easy to use, it has shortcomings such as poor size control and long reaction time [111,112]. Several CDs have been synthesized using the hydrothermal treatment and then used in some methods for preparing $\mathrm{CD}$ /polymer composites. For instance, Issa and Abidin prepared a polyvinyl alcohol (PVA)/nitrogen-doped CD (PVA/CD) composite film [102]. The CDs were prepared using CMC from the waste of empty bunches of fruits from oil palms and a branched PEI. CMC is a natural and cheap carbon precursor, and PEI was chosen as a nitrogen dopant to produce nitrogen-doped CDs. The CDs were encapsulated with PVA polymer. The PVA/CD film had synergistic functionality by enhancing the number of $\mathrm{H}$-bonds for chemisorption compared to the CDs. A representation of the development of the CDs and PVA/CD composites is shown in Figure 2. In [102], CMC and PEI were dispersed in deionized water. Subsequently, the mixture was heated in a Teflon-lined autoclave for $2 \mathrm{~h}$ at $260^{\circ} \mathrm{C}$. The supernatant was centrifuged to gain a clear carbonaceous product. The final product was purified by vacuum filtration to eliminate the precipitation. Then, it was inserted into a dialysis membrane to eliminate the salt ions. Subsequently, PVA/CD film was produced by adding N-CDs to the PVA solution under constant stirring. The acquired hydrogel was placed on a glass substrate and heat to dry for $1 \mathrm{~h}$ at $80^{\circ} \mathrm{C}$. Finally, the PVA/CD film was removed from the surface of the glass substrate to receive a free-standing film. 

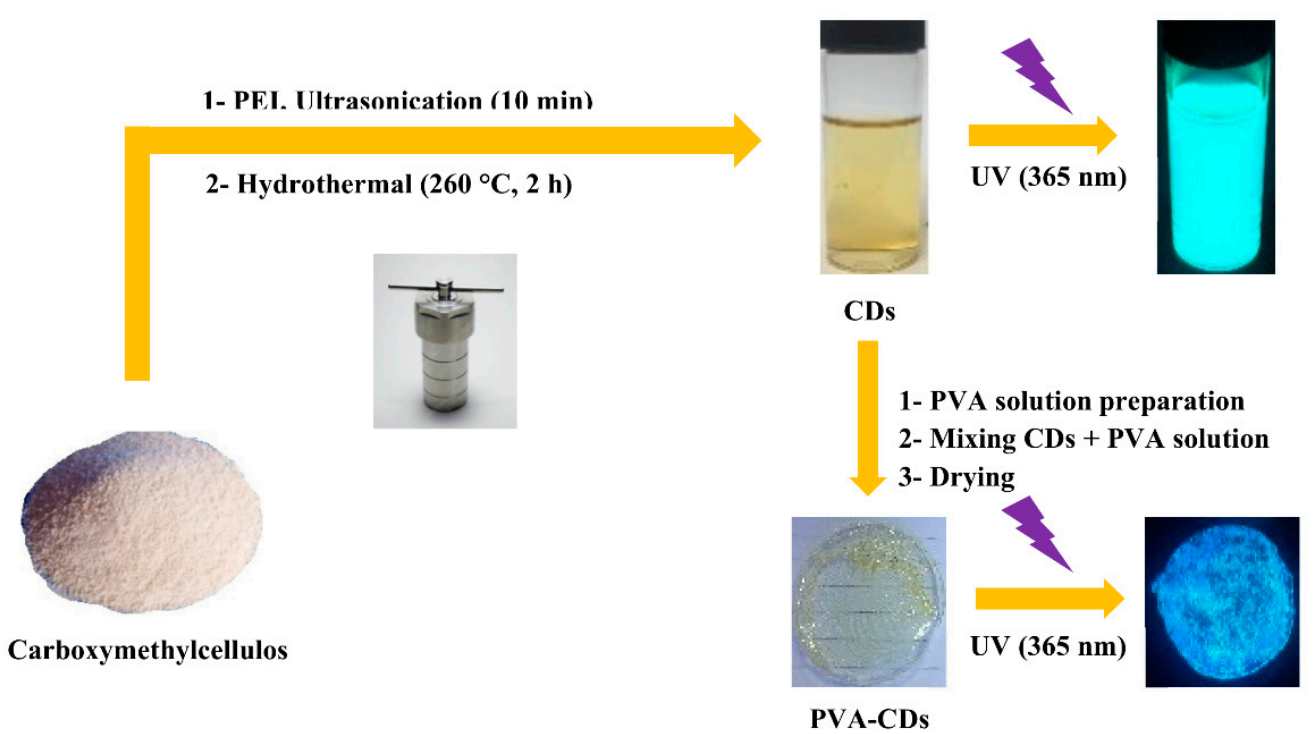

Figure 2. Illustration of preparation of CDs and PVA/CD film. Reprinted with permission from [102]. Copyright (2020) MDPI.

Furthermore, Bai et al. prepared thermoplastic polyurethane elastomer (TPU)/CD bulk composites through hydrothermal-assisted in situ polymerization [96]. The CDs were produced using the hydrothermal method with citric acid and 2AT as the carbon precursor and nitrogen dopant, respectively. Polyurethane is one of the most famous polymer materials [112]. In brief, citric acid and 2AT were dispersed in ultrapure water and heated for $3 \mathrm{~h}$ at $170{ }^{\circ} \mathrm{C}$. Then, the solution was centrifuged, followed by the dialysis of the supernatant. A light yellow powder was received after the freeze-drying process and kept at $4{ }^{\circ} \mathrm{C}$. For preparing TPU/CD composites through in situ polymerization, CDs were dispersed in $\mathrm{N}, \mathrm{N}$-dimethyl formamide (DMF) and inserted in a round-bottomed flask with nitrogen protection. Poly(tetramethylene glycol (PTMG) was inserted under stirring to produce a homogeneous mixture. Afterward, methylene-bis(4-cyclohexylisocyanate) (HMDI) was inserted into the reactor. The reaction was performed for $2 \mathrm{~h}$ at $80^{\circ} \mathrm{C}$ with dibutyltin dilaurate (DBTDL) until isocyanate groups (NCO) were obtained. Finally, 1,4butanediol (BDO) was added to the mixture. The agitator was simultaneously accelerated with a quick viscosity enhancement. A heated mold at $\sim 140{ }^{\circ} \mathrm{C}$ was set up to handle the produced mixture and pressed for $10 \mathrm{~min}$ at $10 \mathrm{MPa}$. The product was in the form of a sheet almost $1 \mathrm{~mm}$ thick. The TPU/CD composites were obtained after curing for $24 \mathrm{~h}$ at $100{ }^{\circ} \mathrm{C}$. In addition, Zheng et al. synthesized $\mathrm{CD} /$ polymer composites via hydrothermal treatment using HMT and polycarbonate as carbon and polymer precursors [104]. After polymerization of the precursors, $\mathrm{CD}$ /polymer composites were prepared in a one-step process. The reaction temperature was as low as $150^{\circ} \mathrm{C}$. The polycarbonate precursor had the advantages of easy manufacture and cheap price. The synthesized composites powders were simply cut or polished into phosphors, which is compatible with the manufacturing process of phosphors. The HMT solution and polycarbonate were placed into a Teflon-line autoclave and heated for $12 \mathrm{~h}$ at $150{ }^{\circ} \mathrm{C}$. After the hydrothermal reaction, the reactor was cooled down naturally. The solution was dialyzed in distilled water for a month.

\subsection{Solvothermal Treatment}

Solvothermal treatment uses almost the same procedure as the hydrothermal treatment method, but the solvent is changed from water to organic solvents. Usually, a carbon precursor with an organic solvent is reacted in a sealed reactor and heated at a high temperature for several hours, followed by separation, purification, and concentration procedures [113]. The controllable heteroatom doping and simple synthesis process make this method a fruitful means of fabricating CDs. The shortcomings of solvothermal treatment are size control difficulty, carbonaceous aggregation during carbonization, long reaction 
time, and problems in solubility [113]. There have been several reports of the preparation of $\mathrm{CDs}$ using the solvothermal method before making $\mathrm{CD} /$ polymer composites. For instance, Bhattacharya et al. constructed FL self-healing gels by reacting CDs derived from some aldehyde precursors with PEI via solvothermal treatment and Schiff base reaction [103]. The self-healing gel was produced via a Schiff base reaction between the primary amine residues in the PEI network and the aldehyde units on the CDs surface. The gels' viscoelastic characteristics could be splendidly arranged by taking control of the $\mathrm{CD}$ and polymer ratios. The preparation and fabrication of the $\mathrm{CD}$ /polymer self-healing gel are illustrated in Figure 3. Three aldehyde building blocks and synthesis conditions used to yield different colored CDs are depicted in Figure 3A. Glutaraldehyde/ethanol, benzaldehyde/ethanol, and cyclooctadiene-aldehyde polymer/chloroform were heated via solvothermal treatment at $150^{\circ} \mathrm{C}, 180^{\circ} \mathrm{C}$, and $180^{\circ} \mathrm{C}$ for $2 \mathrm{~h}, 20 \mathrm{~h}$, and $20 \mathrm{~h}$, respectively. In particular, the aliphatic dialdehyde glutaraldehyde produced green-FL CDs (G-CDs), benzaldehyde was utilized to obtain blue-FL CDs (B-CDs), and a cyclooctadiene-aldehyde polymeric derivative was utilized to produce yellow-FL CDs (Y-CDs). The method of gel interaction, mainly the vital structural role of the aldehyde residues, is depicted in Figure 3B. The CDs showed aldehydes on their surfaces because of the mild reaction conditions and low temperature, which prevented pyrolyzing the precursor molecules [114]. The Schiff base reaction between the plentiful amines within the PEI structure and the aldehyde residues generated imine bonds, stabilizing the CD/PEI gel upon mixing of the CDs and PEI. The gel was synthesized in a chloroform/ethanol solvent because the CDs were insoluble in water. Figure $3 \mathrm{C}$ shows the dynamic covalent imine bonds as the core structural element responsible for the gel's self-healing characteristics. Remarkably, the imine bonds could be immediately broken and reconstructed in mild reaction conditions, substantially enabling mechanical interference and improving the $\mathrm{CD} / \mathrm{PEI}$ gel.

Furthermore, Wang et al. produced solid white-light-emitting phosphors (WCDs@PS), where B-CDs and O-CDs were combined with polystyrene (PS) via a self-assembly technique [73]. PS acts as a linking agent to displace solid matrixes and as the blocking agent to avoid intermolecular FL resonance energy transfer and aggregation-induced quenching of multicolored CDs. The B-CDs and O-CDs were prepared using the solvothermal method. In brief, citric acid and urea were dispersed in DMF. Then, the mixture was thermally heated for $6 \mathrm{~h}$ at $180^{\circ} \mathrm{C}$. The B-CDs and O-CDs were cooled down and separated using silica column chromatography. Then, the B-CDs and O-CDs were re-dissolved in water and freeze-dried to get the powdered CDs. Subsequently, the CDs were mixed with the PS solution under stirring for $4 \mathrm{~h}$. Then, the mixture was centrifuged to eliminate unadsorbed CDs. The precipitates were taken out and freeze-dried. To fabricate WLEDs, WCDs@PS powders and silica gel were mixed and deposited on a GaN-LED chip. The chip was coated to the LED pedestal's bottom. Finally, the device was dried for $1 \mathrm{~h}$ at $150^{\circ} \mathrm{C}$. In addition, Safaei and coworkers fabricated CD/PAN (polyacrylonitrile) composite nanofibers using solvothermal treatment followed by the electrospinning procedure [61]. CDs were prepared from chitosan through the solvothermal method. Typically, chitosan was dissolved in $2 \%$ acetic acid and heated for $16 \mathrm{~h}$ in a Teflon autoclave at $180^{\circ} \mathrm{C}$. After cooling down, the dark brown product was centrifuged to eliminate the larger particles. The CD solution was filtered by a membrane filter. The CDs were dispersed in DMF. The dispersion was stirred at ambient temperature for $2 \mathrm{~h}$. The mixture was sonicated for $2 \mathrm{~h}$ at $25^{\circ} \mathrm{C}$. PAN powder was inserted into the dispersion and stirred for $2 \mathrm{~h}$. Subsequently, the sample was placed in a syringe needle connected to a high-voltage generator. The needle acted as the electrode for the process of electrospinning. The dispersions were inserted from the syringe pump with a feed rate of $0.11 \mathrm{~mL} / \mathrm{h}$ for $3 \mathrm{~h}$. 
A

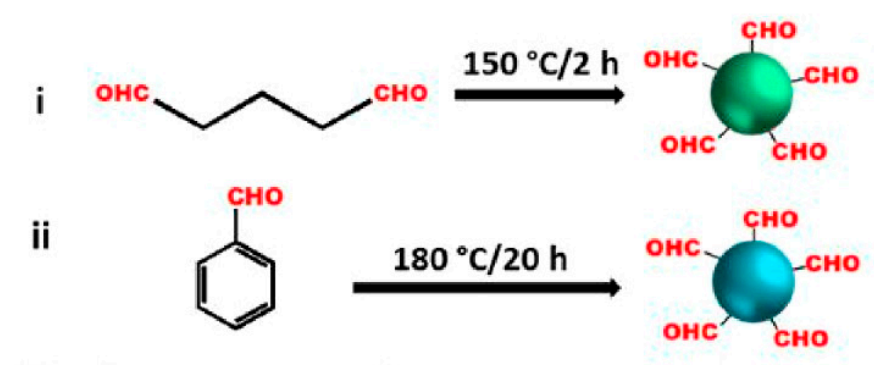

iii
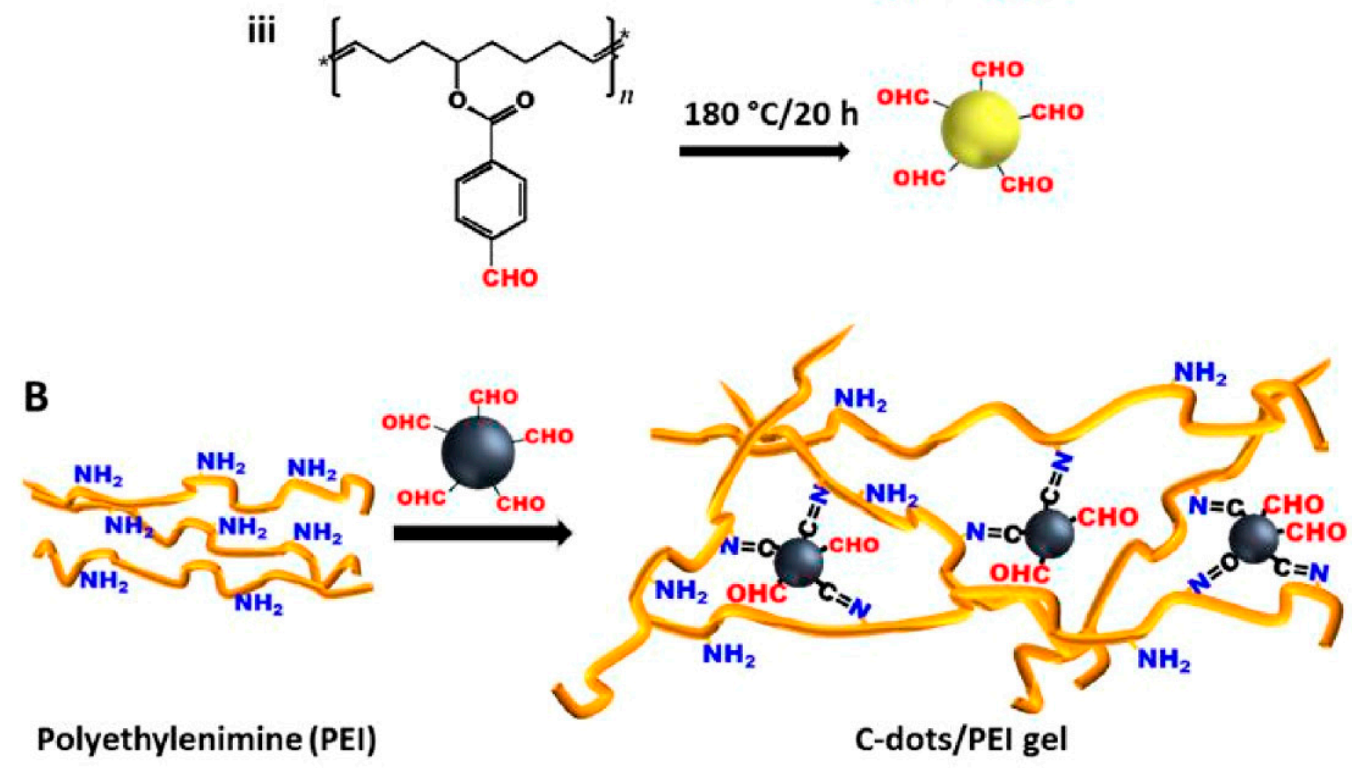

C
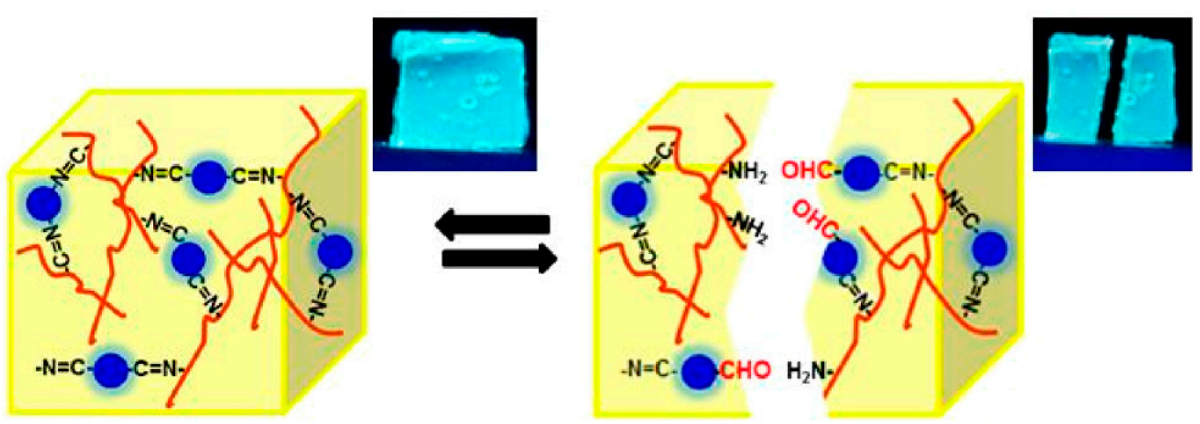

Figure 3. Preparation of the aldehyde-CD/PEI gels. (A) Preparation of aldehyde-CDs derived from an aliphatic dialdehyde (glutaraldehyde, i), aromatic aldehyde (benzaldehyde, ii), and cyclooctadienealdehyde polymer (iii). (B) Interaction of the CD/PEI gel via Schiff base reaction. (C) Self-healing characters of the gel were achieved via reversible imine-bond formation. FL images of the selfhealing event are depicted. Reprinted with permission from [103]. Copyright (2019) American Chemical Society.

\subsection{Microwave Treatment}

The microwave treatment method is an efficient, cheap, scalable, environmentally friendly, and quick strategy to obtain CDs $[115,116]$. Microwave radiation provides rapid heating, which can improve both the quality and yield of CDs [117]. The microwave treatment method has been widely used to prepare CDs but is less frequently used than the hydrothermal method. Usually, the precursor is dispersed in a solvent and the mixture is subsequently heated in microwave equipment. Finally, the resulting CDs are separated and purified. The microwave treatment method has been used to prepare CDs in some literature. For example, Li et al. produced single-hole hollow molecularly imprinted polymers (HMIP) that incorporated CDs (HMIP@CDs) through the microwave-assisted 
sol-gel method [80]. The synthesis process of HMIP@CDs is represented in Figure 4. N, $\mathrm{S}-\mathrm{CDs}$ with carboxyl groups were produced using ammonium citrate and cysteine through a microwave treatment at $750 \mathrm{~W}$ for $2.5 \mathrm{~min}$. A homogeneous cross-linking polymer shell was established at the polystyrene particle's surface via microphase separation and volume shrinkage of the polymer layer after production and swelling of the carboxyl functional polystyrene particle. HMIP@CDs was received by removing the polystyrene particle with dichloromethane. Through the reaction, AEAPMS-CDs were covalently incorporated into HMIP@CDs by the hydrolysis and condensation reactions of APTES and tetraethoxysilane (TEOS) through the microwave-assisted sol-gel method. The polymerization process was performed for $4 \mathrm{~h}$. Moreover, Tian et al. produced CDs@PVA through postsynthetic thermal annealing at $200{ }^{\circ} \mathrm{C}$ [91]. CDs- 1 were derived from citric acid and $\mathrm{NH}_{3}$ solution by microwave treatment. The CDs- 1 were heated at $200{ }^{\circ} \mathrm{C}$ under $\mathrm{N}_{2}$ protection to generate CDs-2. Dehydration and carbonization occurred as outputs of annealing of CDs at $200^{\circ} \mathrm{C}$. Briefly, citric acid was added to $\mathrm{NH}_{3}$ solution and heated in a microwave at $650 \mathrm{~W}$ for $5 \mathrm{~min}$, generating a dark brown liquid. The product was diluted in ethanol and centrifuged to eliminate the agglomerated particles. The supernatant was freeze-dried to gain CDs-1. Then, the CDs- 1 were heated at $200{ }^{\circ} \mathrm{C}$ for $0.5 \mathrm{~h}$ under nitrogen. The product was diluted in ethanol and centrifuged. The supernatant was freeze-dried to gain CDs-2. For the preparation of CDs@PVA composites, CDs- 1 and CDs- 2 were solved in PVA solution, which was spin-coated onto quartz plates and annealed at $80,150,180$, and $200^{\circ} \mathrm{C}$ for $0.5 \mathrm{~h}$.
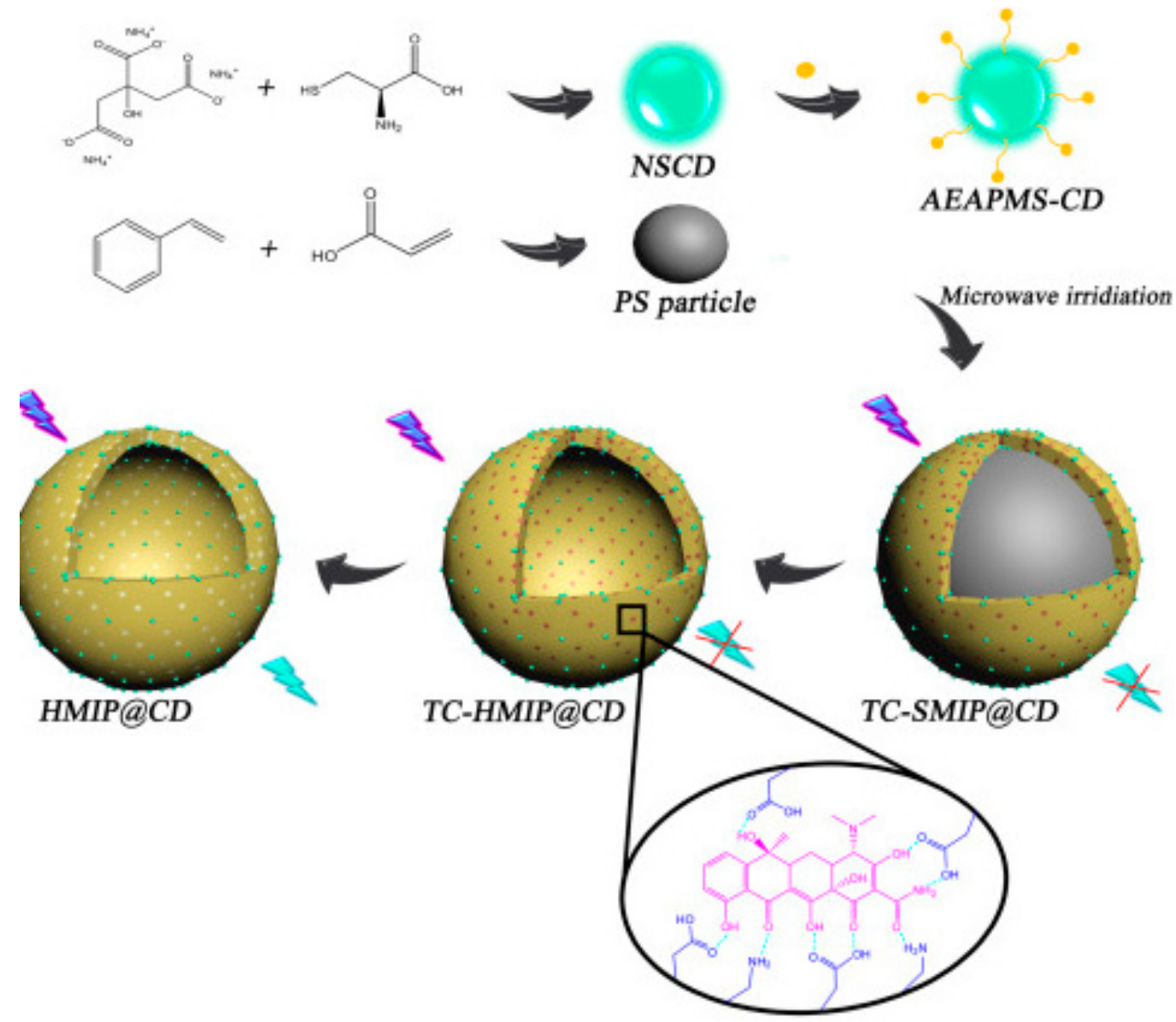

Figure 4. Schematic illustration for preparation of HMIP@CD. Reprinted with permission from [80]. Copyright (2018) Elsevier.

In addition, Yuan et al. fabricated PAN/PEI-CDs through microwave treatmentassisted pyrolysis and interfacial polymerization method [71]. The CDs were easily synthesized via microwave-assisted pyrolysis, attached into a PEI matrix, and afterward dip-coated on a polyacrylonitrile (PAN) support to obtain a composite membrane via inter facial polymerization. PEI was chosen as a polymer matrix because of its great 
solvent-resistance and film-forming capability. Citric acid was dispersed in an ultrapure water/glycerol mixture. Subsequently, diethylenetriamine (DETA) was added to the solution. The mixture was sonicated for about $5 \mathrm{~min}$ and heated in a $750 \mathrm{~W}$ microwave for $5 \mathrm{~min}$. The solution color altered to yellow and afterward to black. The solution was centrifuged using ethanol and then dispersed in water. Then, CDs were obtained using freeze-drying for $48 \mathrm{~h}$. To prepare the composite membranes, the PAN support was tailored into a disc and then inserted in $\mathrm{NaOH}$ solution for $1 \mathrm{~h}$ at $50^{\circ} \mathrm{C}$. The residual $\mathrm{NaOH}$ was eliminated by neutralization with water. The hydrolyzed PAN support was kept in water. A specific number of CDs were dissolved into water under stirring, and a PEI solution was stirred. Then, the solution of CDs and PEI were mixed under stirring to obtain a PEI-CD solution. Subsequently, the mixture was cast onto the PAN support layer and maintained for $10 \mathrm{~min}$. After eliminating the excess solution, n-hexane and TMC solution were cast onto the PEI-CD surface and allowed for 2 min to carry out a cross-linking reaction. Afterward, the membrane was dried for about $20 \mathrm{~min}$ in air and then for $2 \mathrm{~h}$ at $60^{\circ} \mathrm{C}$ to remove the remaining n-hexane and complete the cross-linking reaction, generating PAN/PEI-CD composite membranes.

\subsection{Pyrolysis/Thermal Decomposition}

Pyrolysis treatment is a simple method to produce CDs. It is an irreversible thermal decomposition wherein the precursor decomposes at a high temperature. It entangles chemical and physical alterations of precursors, generating solid black carbon material [118]. Pyrolysis is a fast, facile, and environmentally friendly method, but it is nonscalable and generates a broad size distribution [111]. Generally, pyrolysis is carried out at a high temperature with controlled pressure. The resulting black carbon material can be purified to gain the CDs. For instance, Sun and Wu prepared three CDs from carboxyl, amino, and sulfonic acid groups and combined them into the polyamide layer of thin-film nanocomposite (TFN) membranes through pyrolysis-assisted interfacial polymerization [82]. The prepared CDs were carboxylic CDs (CCDs), amino CDs (NCDs), and sulfonated CDs (SCDs). The scheme of the preparation process of these CDs is depicted in Figure 5A. CCDs, NCDs, and SCDs were prepared by directly pyrolyzing citric acid, citric acid/branched polyethyleneimine (BPEI), and citric acid/poly(sodium 4-styrene sulfonate) (PSS), respectively. The preparation of TFN membranes combined with various CDs through interfacial polymerization is depicted in Figure 5B. Initially, three kinds of CDs were dissolved in piperazine (PIP) solution by ultrasonic dispersion. Afterward, the support membranes were inserted in the PIP solution, and the excess solution was removed from the membrane surface. Then, the PIP-saturated support membranes were inserted into the organic phase, composing trimesoyl chloride (TMC) in cyclohexane. After eliminating the remaining cyclohexane, the membranes were heated at $70{ }^{\circ} \mathrm{C}$ for $0.5 \mathrm{~h}$ for further polymerization and then kept in deionized water.

Furthermore, Koulivand et al. developed CD-modified PES through a pyrolysisassisted nonsolvent induced phase inversion technique [70]. CDs were prepared using a simple pyrolysis method. In brief, citric acid in a beaker was heated for $55 \mathrm{~min}$ at $160^{\circ} \mathrm{C}$. Under stirring, it was neutralized by $\mathrm{NaOH}$ solution, which was then freeze-dried to receive powdered CDs. Subsequently, the CD-modified PES membranes were produced through the nonsolvent induced phase inversion method. First, the CDs were inserted into a flask containing dimethylacetamide (DMAc) as a polymer solvent. The mixture was stirred for a day to disperse the CDs. Subsequently, polyvinyl pyrrolidone (PVP) and PES were dispersed into the solution under stirring. The solutions were degassed at $50{ }^{\circ} \mathrm{C}$ for $2 \mathrm{~h}$ in an oven. After cooling down, thin films of the solutions were cast by a casting knife onto clean glass. Afterward, the films were directly immersed in a water bath to thicken and produce the membranes. Finally, they were stored in water overnight, dried at $25^{\circ} \mathrm{C}$, cut off, and immersed in water for $12 \mathrm{~h}$. 

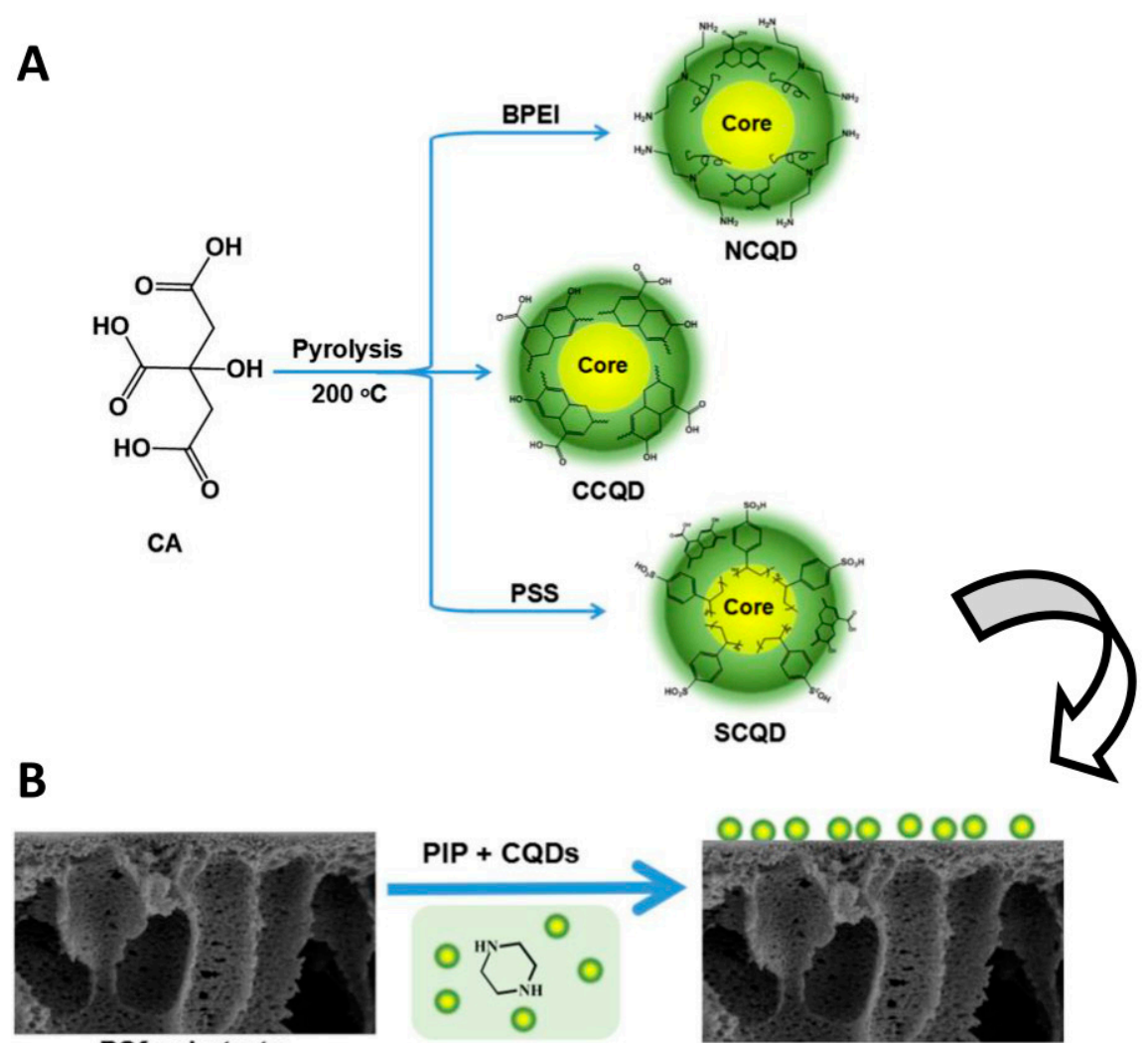

PSf substrate
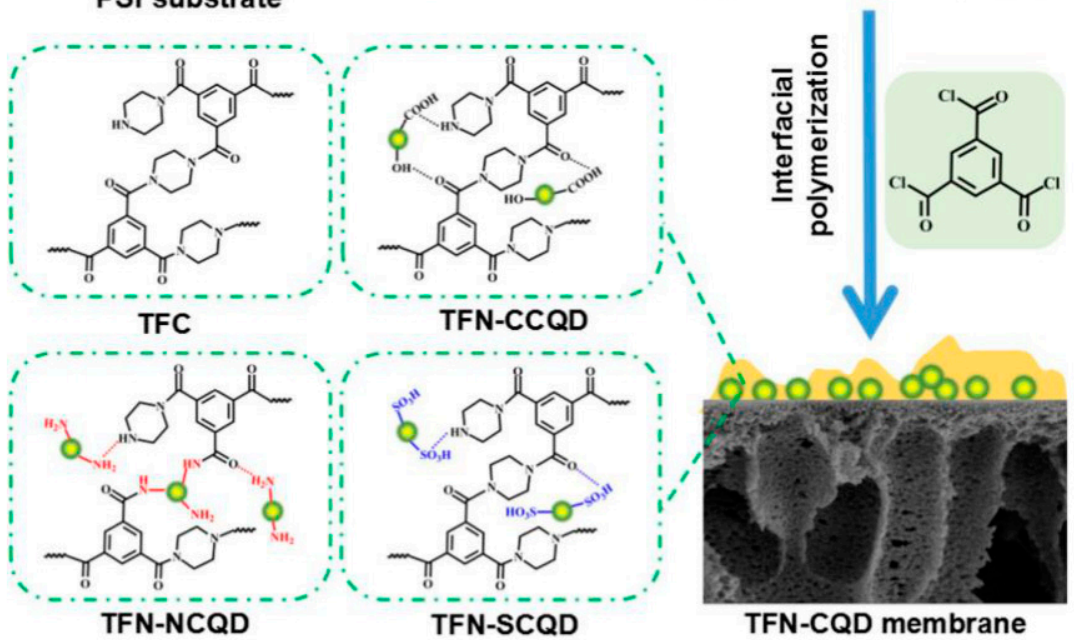

Figure 5. (A) Representation of the preparation process of three CDs. (B) Schematic representation for the production of various TFN-CD membranes through interfacial polymerization. Reprinted with permission from [82]. Copyright (2018) Elsevier.

Moreover, Rimal, Shishodia, and Srivastava produced CDs from oleic acid, and the CDs were incorporated in a cellulose acetate polymer matrix to obtain a composite [65]. The procedure involved the pyrolysis method. In brief, $\mathrm{NaOH}$ was dissolved in double-distilled water. $\mathrm{NaOH}$ and double-distilled water were mixed under stirring until a transparent solution was obtained. Oleic acid was subsequently placed into another beaker and heated at $230-260{ }^{\circ} \mathrm{C}$ with constant stirring for a while. The solution was then filtered and sonicated. Afterward, the CD solution was evaporated to isolate anhydrous CDs. The solid CDs were dried and dispersed in ethanol. CD/polymer composites were prepared through the blending method. Cellulose acetate was taken in dimethylformamide and stirred magnetically. Then, CD solution was dissolved in DMF, stirred, and sonicated. 
Subsequently, the mixture was magnetically stirred, transferred to a Petri dish, and allowed to rest with ordinary evaporation. Finally, the sample was heated for $2.5 \mathrm{~h}$ at $60{ }^{\circ} \mathrm{C}$.

\subsection{Ultrasonic Treatment}

Ultrasonic treatment is an ecofriendly method with the benefits of simple, mild work conditions, green sources of energy, and the possibility to obtain CDs with controlled physical and chemical characteristics with low toxicity $[119,120]$. Typically, a carbon precursor in an appropriate solvent is sonicated for a desirable time. The radiation energy is used for condensation and carbonization, resulting in the formation of CDs [121]. This method has been seldom used to prepare CDs for CD/polymer composites. For instance, Kumar et al. prepared PVA-N@CD nanocomposites wherein N@CDs were embedded in PVA polymer [74]. Figure 6 exhibits a probable procedure for the preparation of PVAN@CD composites through the ultrasonic treatment and stirring/drop-casting methods. It exhibits the chemical interactions through $\mathrm{H}$-bonding among the PVA long chain and various N@CDs' surface functional groups. In [74], CDs were produced by sonication. N@CDs were synthesized from a BSA solution. The PVA-N@CDs were produced via stirring of the N@CDs aqueous solution in PVA solution. PVA was inserted in a beaker containing water. The PVA-water mixture was maintained under constant stirring for $2 \mathrm{~h}$ at $60{ }^{\circ} \mathrm{C}$. This clear PVA solution was cooled down, and N@CDs solution was added under continuous stirring, generating a clear, light yellow, slightly viscous solution. The $\mathrm{pH}$ values of the $\mathrm{N} @ \mathrm{CD}$ s solution and the PVA solution were maintained similarly and were kept at 6-8 for more stable composites. The composite solutions were utilized to make a thin film by a drop-casting method, and the solvent was evaporated naturally.
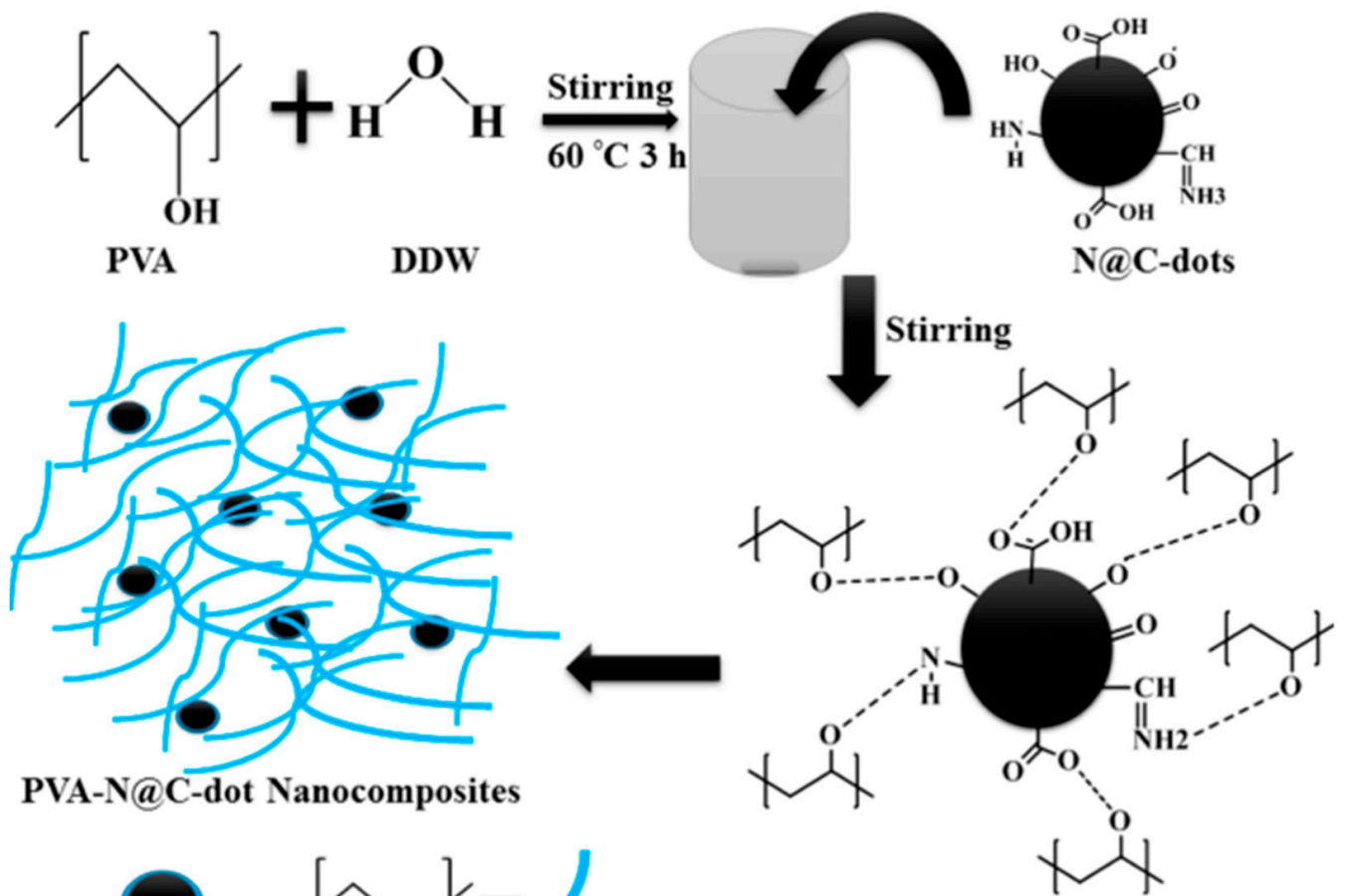

PVA-N@C-dot Nanocomposites<smiles>CC(C)=C(C)C(O)CC(C)(C)CC(C)(C)C</smiles>

Figure 6. Illustration of the preparation of PVA-N@CDs composites and the appropriate H-bonding interaction between N@CDs and PVA leading to PVA chains' cross-linking to form the PVA-N@CDs film. Reprinted with permission from [74]. Copyright (2017) American Chemical Society.

Furthermore, Li et al. fabricated a pyrophosphate ion (PPi)-responsive alginate hydrogel utilizing $\mathrm{Cu}^{2+}$ as a crosslinking agent to form $\mathrm{Cu} / \mathrm{Alg}$ gel [68]. CDs as a visual indicator were incorporated in the $\mathrm{Cu} / \mathrm{Alg}$ gel matrix to yield the composite of CDs@Cu/Alg. The 
CDs were prepared using an ultrasonic method. In brief, $\mathrm{NaOH}$ was added to $\mathrm{CPC}$ aqueous solution and mixed well. Then, the mixture was ultrasonicated for $30 \mathrm{~min}$ at $25^{\circ} \mathrm{C}$. Subsequently, the reaction was terminated by adjusting the $\mathrm{pH}$ of the solution to neutral with $\mathrm{HCl}$, followed by dialysis to remove unreacted reagents. Finally, the purified products were dried at $65^{\circ} \mathrm{C}$ and redispersed in ultrapure water. The $\mathrm{Alg} / \mathrm{Cu}$ gel was prepared by simple mixing of aqueous alginate solution and $\mathrm{CuCl}_{2}$ solution. A gelation assay was carried out to form an insoluble hydrogel. Then, the hydrogel was washed with ultrapure water to remove the unreacted reagent. To prepare $\mathrm{CDs} @ \mathrm{Alg} / \mathrm{Cu}$, CDs were first mixed with alginate aqueous solution. Then, the $\mathrm{CuCl}_{2}$ aqueous solution was added to trigger the gelation of alginate. After the reaction, the insoluble products were collected by centrifugation and followed by washing with ultrapure water. For PPi-stimulated sol-gel transition of CDs@Alg/Cu, PPi aqueous solution with different concentrations was added to the test tube containing $\mathrm{CDs} @ \mathrm{Alg} / \mathrm{Cu}$ and mixed well. The reaction took place at room temperature with gentle shaking.

\section{Optical Properties of CD/Polymer Composites}

The optical properties of CDs are very significant for their various potential applications. Most CDs are FL over the visible spectrum, extending into the near-IR region [122]. CDs commonly contain carbon, oxygen, and certain heteroatoms such as nitrogen, boron, sulfur, silicon, and phosphorus [16]. Most CDs have no significant absorption in the visible range but emit a multicolor emission from blue to red [16]. Herein, we discuss the optical characteristics of $\mathrm{CD} /$ polymer composites, including UV-vis absorption characters and FL properties. Hu et al. obtained CD/polymer composites with FL properties [89]. The original FL characteristics of CDs can be kept in the polymer system [123]. Figure 7A shows that the CD/PVA composite solution exhibited a quench-resistant FL character. It has excellent viscosity and can be utilized to make FL ink for distinct patterns, presenting bright solid-state FL at ambient temperature (Figure 7B). Afterward, CD/PVA films were produced and exhibited good work on light transmission and ductility (Figure 7C). The FL spectra of CDs/PVA exhibit their emission wavelengths at $444 \mathrm{~nm}, 520 \mathrm{~nm}, 550 \mathrm{~nm}$, and $585 \mathrm{~nm}$. The CD/PVA films were radiated under UV light, and they emitted bright FL color with QYs of $5.3 \%, 12.4 \%, 8.9 \%$, and $6.9 \%$ for B-, G-, Y-, and O-emission films, respectively (Figure 7D). The FL excitation and emission spectra of the CD/PVA solutions/films and $\mathrm{CD}$ solution were similar, denoting that the $\mathrm{CDs}^{\prime}$ emissive characters were well-maintained in PVA.

Besides FL color, CD/polymer composites have their own FL properties based on excitation and emission wavelengths and UV-vis absorption behavior. For instance, Wang et al. prepared MCOFs@MIPs@CDs by using citric acid and APTES as a carbon precursor and a functional monomer, respectively [75]. The FL properties of the composites were investigated by measuring the whole emission spectra of the composites at various excitation wavelengths from 320 to $410 \mathrm{~nm}$. The optimum excitation was $370 \mathrm{~nm}$, whereas the optimum emission wavelength was $\sim 470 \mathrm{~nm}$ (Figure $8 \mathrm{~A}, \mathrm{~B}$ ). The composites without 2,4,6-trinitrophenol (TNP) showed stronger FL signal than those with TNP, and the FL intensity of those without TNP was recovered to $91.3 \%$ of that of MCOFs@NIPs@CDs (Figure 8C). The FL stabilization phenomenon is due to the incorporated CDs being much more stable because of the MCOFs and MIP shell protection [124]. CD/polymer composites also show UV-vis absorption behavior. For instance, CD/PVA films that were synthesized by Zhao et al. exhibited broad band absorption over the visible light range (Figure $8 \mathrm{D}$ ). The adsorption peak was centered at about $489 \mathrm{~nm}$, while the adsorption at $532 \mathrm{~nm}$ was still high. Furthermore, TPU/CDs synthesized by Bai et al. exhibited wide absorbance bands in UV-vis wavelength ranges, identical to those of the constituent CDs [96]. The CDs were embedded into the composites without altering their fundamental optical properties [125]. Each peak intensity increased along with the concentration of the CDs. The interaction among CDs increased with the level of CDs, and CDs' dispersion in the TPU matrix also altered as the level of CDs increased. Accordingly, the CDs in each composite exhibited 
various energy gaps and surface states. Therefore, the absorption peak center showed a red shift [126]. Table 3 presents the features of the optical properties of multiple CD/polymer composites, including excitation wavelength $\left(\lambda_{\mathrm{Ex}}\right)$, emission wavelength $\left(\lambda_{\mathrm{Em}}\right), \mathrm{QYs}, \mathrm{UV}-$ vis absorption peak (Abs.), and FL color. The QYs of CD/polymer composites were rarely calculated. Generally, the optical properties of CDs and CD/polymer composites have similar patterns because the polymers do not alter the optical characters of bare CDs. The FL emission colors of the CD/polymer composites were green $(G)$, blue (B), cyan (C), red $(\mathrm{R})$, yellow $(\mathrm{Y})$, and orange $(\mathrm{O})$, depending on their FL emission wavelengths.

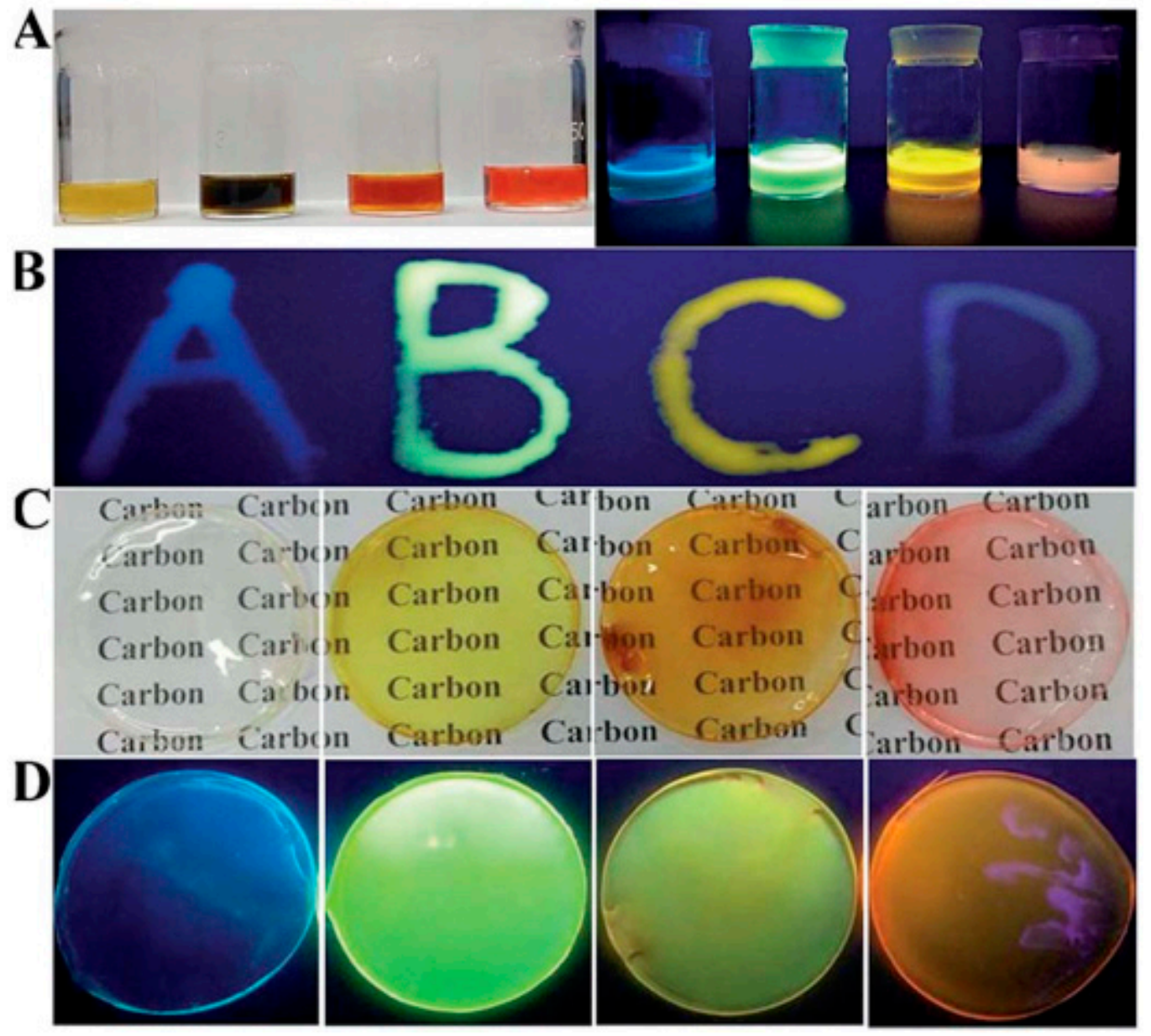

Figure 7. (A) Images of B-, G-, Y-, and O-CD/PVA solutions under daylight and UV light. (B) Pictures of four characteristics under UV light with $\mathrm{B}_{-}, \mathrm{G}_{-}^{-}, \mathrm{Y}_{-}$, and $\mathrm{O}-\mathrm{CD} / \mathrm{PVA}$ solutions as FL ink. (C) Images of B-, G-, Y-, and O-CD/PVA films under daylight. (D) Images of B-, G-, Y-, and O-CD/PVA films under UV light. Reprinted with permission from [89]. Copyright (2019) The Royal Society of Chemistry.

In addition, the physicochemical properties of CDs influenced the optical properties of $\mathrm{CD}$ /polymer composites. The absorbance and FL behaviors of CD/polymer composites were primarily derived from the nature of the CDs. In general, the average size of the CDs was less than $10 \mathrm{~nm}$, and the largest size was $60 \mathrm{~nm}$ [127]. The superior characteristics of QDs are the effect of quantum confinement taking place when the QDs' size is lower than their Bohr exciton radius $[128,129]$. The primary result of the quantum confinement effect is that the band gaps of CDs exhibit dependence on their size, leading to various sizedependent optical characteristics of the CDs [128]. CDs separated and purified by column chromatography generated various sizes of CDs with small size distributions [3]. The FL characteristics differed explicitly with different size of CDs. The sizes of CDs exhibited different optimum FL emission peak centers. In addition to the size, the FL may derive from 
intrinsic and defect states of emission. The presence of $\mathrm{C}=\mathrm{C}, \mathrm{C}=\mathrm{O}, \mathrm{C}-\mathrm{O}$, and $\mathrm{O}-\mathrm{C}=\mathrm{O}$ bonds suggests that $\mathrm{CDs}$ have various functional groups. The functional groups may contribute to the UV-visible absorption characteristics and play a prominent role in assigning the absorption peak position [130]. FL was associated with the surface state connected to the hybridization structure of the functional groups and the carbon core. Most carboxyl and amide groups contributed to green FL, while hydroxyl groups contributed to blue FL [131]. The enhanced oxidation degree and the substitution of hydroxyl groups by amino groups induced a red shift in FL emission [89]. Therefore, the FL characteristics of CD/polymer composites were affected by the optical selection of different sizes of CDs and various emissive traps on the CDs' surfaces. For CDs with identical surface functional groups, the gel-column-separated fractions of various FL QYs have commonly been associated with various levels of surface passivation/functionalization, in which less functionalization/passivation resulted in less FL QYs [132,133]. The significant enhancements in QY of CDs in polymer films compared to those in solutions were correlated mainly with the increased surface passivation effect of CDs in the film environment [122]. However, the absorption of CDs owes to the $\pi$-plasmon transitions in the carbon core, and the film has no valuable impact on these transitions [122].
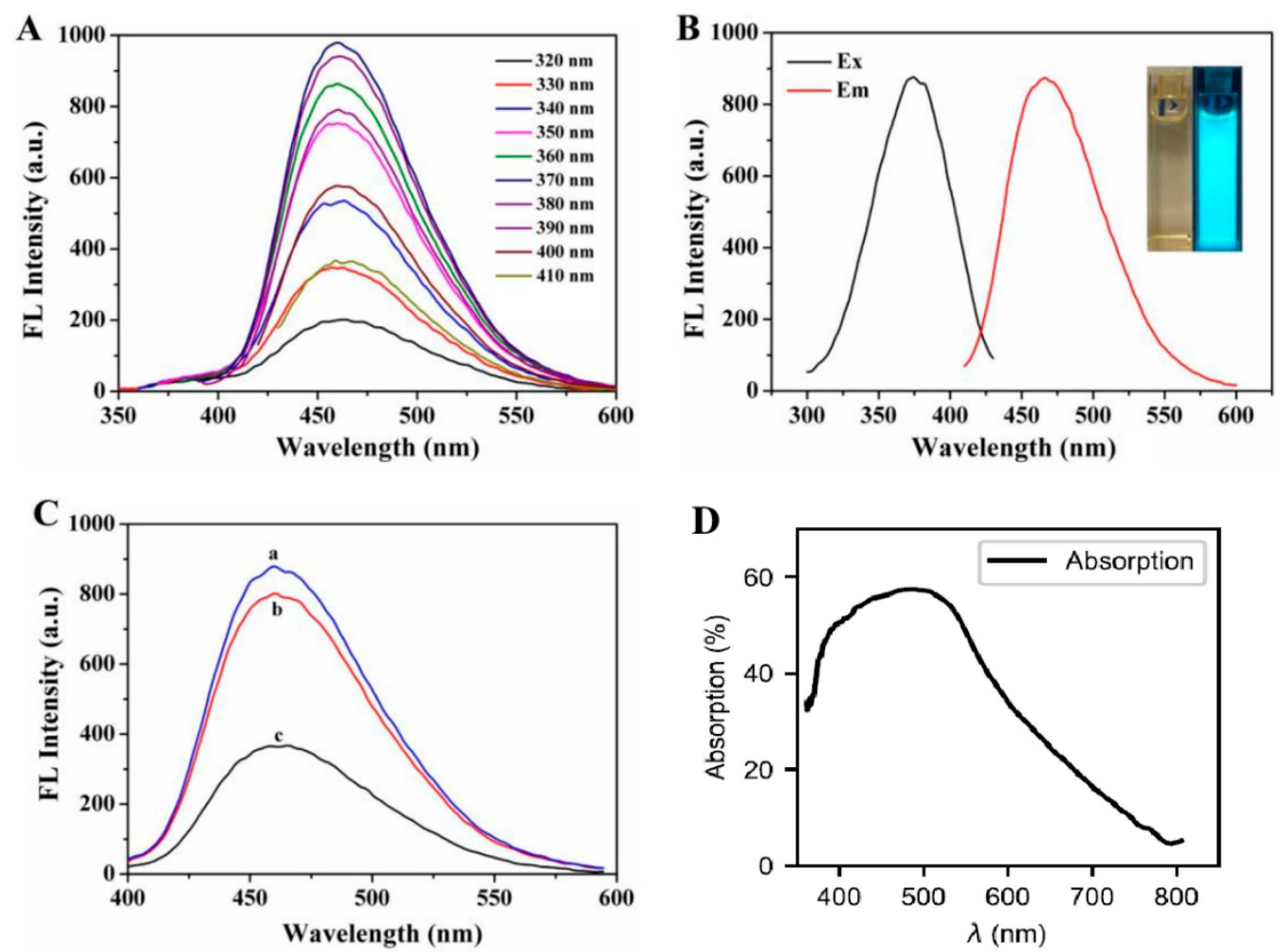

Figure 8. (A) FL emission spectra of MCOFs@MIPs@CDs with various excitation wavelengths (320-410 nm). (B) Maximum FL excitation and emission spectra of MCOFs@MIPs@CDs. The inset shows images of the MCOFs@MIPs@CDs solution under daylight and UV light of $365 \mathrm{~nm}$. (C) FL emission spectra of MCOFs@NIPs@CDs (curve a), MCOFs@MIPs@CDs without TNP (curve b), and MCOFs@MIPs@CDs with TNP (curve c). (D) The UV-vis absorption spectra of TPU/CD nanocomposites. Reprinted with permission from [75,101]. Copyright (2019) Elsevier and Copyright (2020) Springer Nature. 
Table 3. The optical properties of several CD/polymer composites, including FL and UV-vis absorption properties.

\begin{tabular}{|c|c|c|c|c|c|c|}
\hline Composites & $\lambda_{\mathrm{Ex}}(\mathrm{nm})$ & $\lambda_{\mathrm{Em}}(\mathrm{nm})$ & QY (\%) & Abs. (nm) & FL Color & Ref. \\
\hline CD/PVA film & 532 & 585 & $\mathrm{~N} / \mathrm{A}$ & 489 & $\mathrm{~N} / \mathrm{A}$ & [101] \\
\hline PVA/CD film & 420 & 530 & $\mathrm{~N} / \mathrm{A}$ & $\sim 220, \sim 290$ & G & [56] \\
\hline CDs@MIPs & 370 & 470 & 51.8 & 370 & $\mathrm{~B}$ & [63] \\
\hline $\mathrm{CS} / \mathrm{PVA} / \mathrm{CDs}$ & 360 & 436 & $\mathrm{~N} / \mathrm{A}$ & 360 & $\mathrm{C}$ & [95] \\
\hline PVA/CDs & 360 & $\sim 470$ & 47 & $294 / 340$ & $\mathrm{~B}$ & [102] \\
\hline $\begin{array}{c}\text { PE/CDs, PP/CDs, } \\
\text { PEG/CDs }\end{array}$ & 350,380 & $\sim 450-470$ & $2.5-38$ & $\mathrm{~N} / \mathrm{A}$ & $\mathrm{B}, \mathrm{G}, \mathrm{R}$ & [66] \\
\hline C-MIP & 540 & 610 & $\mathrm{~N} / \mathrm{A}$ & $\mathrm{N} / \mathrm{A}$ & $\mathrm{R}$ & [88] \\
\hline MCOFs@MIPs@CDs & 370 & 470 & $\mathrm{~N} / \mathrm{A}$ & $\mathrm{N} / \mathrm{A}$ & $\mathrm{C}$ & [75] \\
\hline TPU/CDs & 400 & 470 & 68 & 335,399 & B & [96] \\
\hline CD-polymer & 455 & 550 & 14.86 & $200-500$ & $\mathrm{Y}$ & [104] \\
\hline $\mathrm{CDs} / \mathrm{Fe}_{3} \mathrm{O}_{4} @ \mathrm{MIPs}$ & 370 & 470 & $\mathrm{~N} / \mathrm{A}$ & $\mathrm{N} / \mathrm{A}$ & B & [76] \\
\hline CD/PVA films & $\begin{array}{c}365,450,420 \\
400\end{array}$ & $444,520,550,585$ & $5.3-12.4$ & $\begin{array}{c}365,450,420 \\
400\end{array}$ & $\mathrm{~B}, \mathrm{G}, \mathrm{Y}, \mathrm{O}$ & [89] \\
\hline CDS@Cu/Alg & 400 & 513 & $\mathrm{~N} / \mathrm{A}$ & $\mathrm{N} / \mathrm{A}$ & G & [68] \\
\hline CQDs@MIPs & 360 & 453 & $\mathrm{~N} / \mathrm{A}$ & $\sim 260$ & $\mathrm{~N} / \mathrm{A}$ & [58] \\
\hline C-dots/PVB film & 400 & 550 & $\mathrm{~N} / \mathrm{A}$ & $353,410,500$ & G-B, O-R & [50] \\
\hline MIPs-GSCDs & 340 & 410 & 18.6 & $\sim 275$ & $\mathrm{~N} / \mathrm{A}$ & [59] \\
\hline CD-polymer & $\mathrm{N} / \mathrm{A}$ & 470 & 50 & 250,300 & G & [65] \\
\hline $\mathrm{CDs@SiO} 2 @ \mathrm{MIPs}$ & 380 & $>450$ & $\mathrm{~N} / \mathrm{A}$ & 288 & $\mathrm{~N} / \mathrm{A}$ & [60] \\
\hline WCDs@PS & 380 & $\sim 590$ & $10.7,15.2$ & $\mathrm{~N} / \mathrm{A}$ & $\mathrm{O}, \mathrm{B}$ & [73] \\
\hline CDs@MIPs & 360 & 450 & $\mathrm{~N} / \mathrm{A}$ & $250-300$ & B & [69] \\
\hline C-dot/PEI gel & 470 & $\sim 565$ & $1.9-4$ & $290,340,380$ & $\mathrm{C}$ & [103] \\
\hline Y-CD/PVA, Y-CDs/CS & 420 & 550 & 6 & $\begin{array}{c}234,259,285 \\
420\end{array}$ & $\mathrm{Y}$ & [67] \\
\hline CDs@PVA & 365 & $420-440$ & $\mathrm{~N} / \mathrm{A}$ & $\sim 350$ & $\mathrm{~B}$ & [91] \\
\hline C-dots/PVA & 360 & 459 & 8.64 & 282,341 & G & [57] \\
\hline HMIP@CDs & 390 & 503 & $\mathrm{~N} / \mathrm{A}$ & $\sim 300$ & $\mathrm{~N} / \mathrm{A}$ & [92] \\
\hline BMIP@CDs & 425 & 520 & $\mathrm{~N} / \mathrm{A}$ & $\mathrm{N} / \mathrm{A}$ & $\mathrm{N} / \mathrm{A}$ & [64] \\
\hline CD-MIPGlcA & 445 & $\sim 500$ & 0.97 & $\sim 350$ & B & [62] \\
\hline $\begin{array}{c}\text { Poly(VPBA-AAm)- } \\
\text { CDs }\end{array}$ & 900 & 515 & $\mathrm{~N} / \mathrm{A}$ & 241 & B & [99] \\
\hline PAN/CQD nanofibers & $350,477,530$ & $560,598,660$ & $\mathrm{~N} / \mathrm{A}$ & $314,316,318$ & $R, G, B$ & [61] \\
\hline PVA-N@C-dots & 390 & $\sim 460$ & 44 & 286,355 & C & [74] \\
\hline
\end{tabular}

The concentration of the CDs also affected the FL intensity or wavelength. At low concentrations, the interaction between the polar groups reduces, while high numbers of polar groups tend to establish aggregations [134]. The QY and the production yield of $\mathrm{CD} /$ polymer composites were affected by the mixture composition and amount ratio between CDs and polymeric molecules. Fernandes et al. reported that ethanolamine (EA) was converted to CDs about $28 \%$ and $20 \%$ in PEG/CD and PE/CD composites, respectively [66]. Under similar conditions, EA was converted to CDs about $9 \%$ without addition of polymer. The dispersion of EA in the polymeric matrix decreases its volatilization, improving the QY and yield of the CDs. Wang et al. observed the effect of the PS/WCD mass ratio on the FL characteristics of WCD@PS composites [73]. When increasing the feed ratio from 1:1 to 2:1, the FL intensities at 430 and $590 \mathrm{~nm}$ were decreased. The excess PS exhibited a cloudy mixture and led to the FL quenching of the WCDs. Meanwhile, inadequate PS resulted in a low yield of WCD@PS composites, even though the FL intensity still maintained stable. Hence, they set the feed ratio of PS/WCDs to 1:1. We deduce that the amount and nature of each precursor has a significant impact on the FL QY as well as the production yield of the composites. Based on the aforementioned factors related to the optical properties of $\mathrm{CD} /$ polymer composites, a pictorial representation of interaction between the $\mathrm{CDs}$ and polymer, as well as some factors to improve/correct the optical properties and production yield of $\mathrm{CD}$ /polymer composites, is depicted in Figure 9. The surface functional groups on the $\mathrm{CDs}$ can create $\mathrm{H}$-bonds with the pendant polar groups presented in polymer matrix. 
The H-bond interaction informs the equal distribution of CDs in the polymer matrix. The adjustment of some factors mentioned in the scheme could help to produce $\mathrm{CD} /$ polymer composites with desired optical characteristics and optimum production yield.

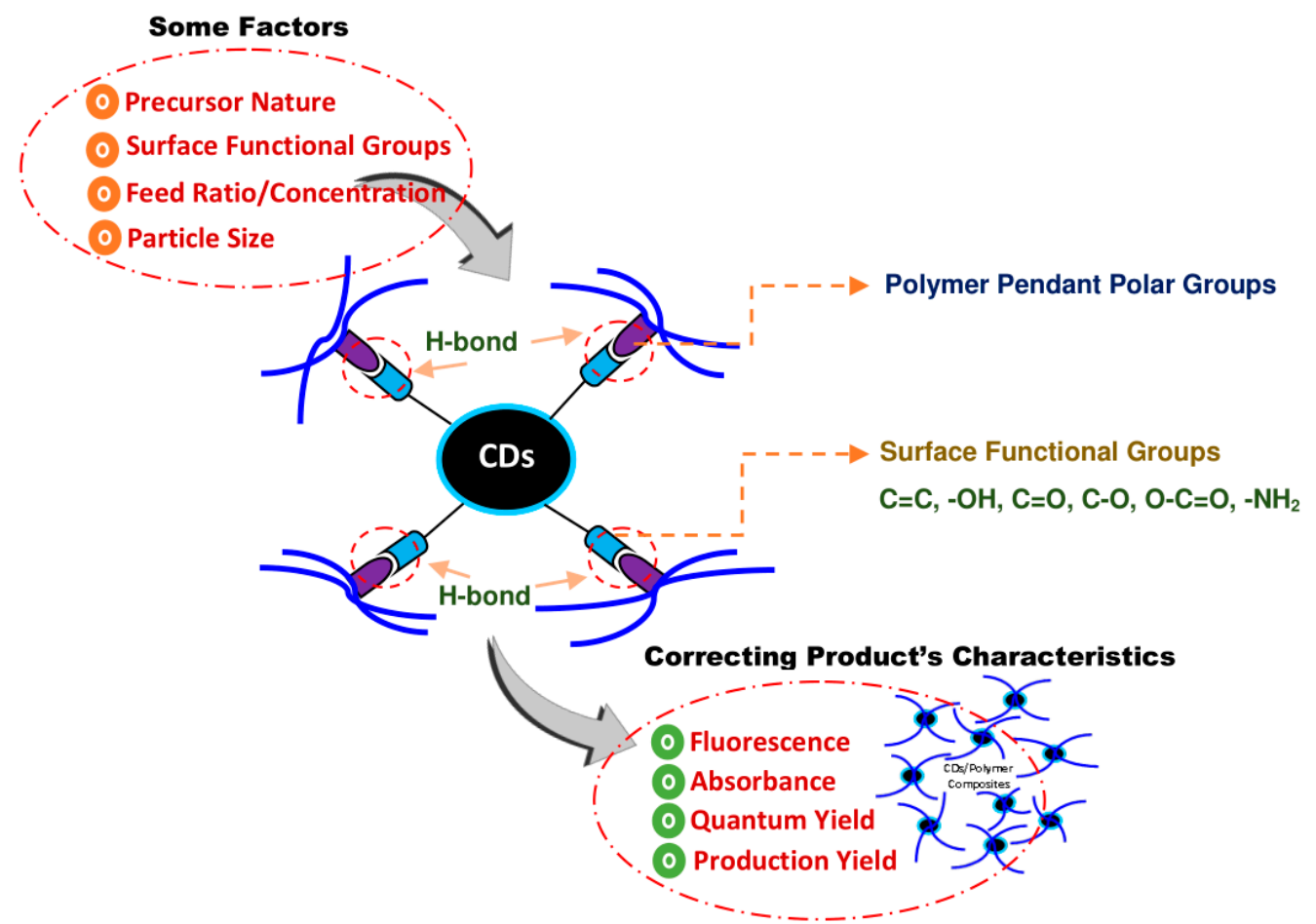

Figure 9. A pictorial representation of the interaction between CDs and a polymer to form $\mathrm{CD}$ /polymer composites and some factors to improve the optical properties and production yield of the composites.

\section{Coating Characteristics of CD/Polymer Composites}

The coating characteristics of $\mathrm{CD}$ /polymer composites are an important parameter for achieving better composites. CDs can increase the physisorption-assisted coating of polymer chains onto their surface. The polymers can act as stabilizers for the CDs. The polymer chains have a high affinity to attach to the CDs' surface [135]. CDs act as physisorption fix sites, and particularly as physical cross-linking points, in the composites. The cross-linking points increase the mechanical strength of the composites. Hazarika et al. revealed that $\mathrm{CD}$ /polymer composites showed two to six times better strength than pristine polymer film [136]. These composites also showed high thermal stability, increased glass transition temperature $\left(\mathrm{T}_{\mathrm{g}}\right)$, and good chemical resistance due to the interfacial adhesion between CDs and polymer chains or physicochemical interactions. Yang et al. observed that CD/TFC (thin film composite) membranes had no damage after being folded in half, showing flexible and strong membranes with various added concentrations of CDs [100]. No valuable alteration of $\mathrm{CDs}$ ' morphology was obtained after coating with polyethersulfone (PES) substrates. The TFC membranes without CDs exhibited a flat surface. With increasing CD loading, small particles were observed on the membrane surface. As the number of CDs increased, the crystallinity of the interfacial polymerized layer was dramatically enhanced. The thickness of the selective layer of membranes was similar, at around $100 \mathrm{~nm}$, meaning that CDs did not affect the thickness of the interfacial polymerization (IP) layer. Higher PEI levels could induce thicker polyamide layers, generating lower water fluxes, which was beneficial for solute retention. Increasing CD concentration led to a reduction of water permeability.

Furthermore, Wang et al. revealed that a measured TEM image of CDs@MIPs showed a spherical shape with a bit of adhesion [63]. The degree of adhesion of CDs@NIPs was more serious, and the particle sizes were much smaller. The template affected the composite 
structure during the preparation process. Li et al. utilized CDs to modify a polyamide reverse osmosis membrane [97]. CDs were coated onto the active layer of the thin film membrane during the IP process, inducing increased membrane hydrophilicity, porosity, and permeability. The thickness of the selective layer was decreased, and the desalination was improved. In addition, Shao et al. reported the preparation of a TFC layer by PIP and TMC in an IP process to establish a nodule structure with a cross-sectional thickness of 80-120 nm [98]. The PES substrate was coated with a mixture of CDs, CMPI, and $\mathrm{NaOH}$ before the IP process. CMPI was utilized to activate the carboxyl groups on the CDs' surface to stabilize the bonding between the CDs and the polyamide selective layer. The remaining $\mathrm{NaOH}$ from the $\mathrm{CD}$-coating step might act as a $\mathrm{HCl}$ acceptor produced during the IP process. The PES substrate was pretreated by PDA before depositing the mixture. The PDA layer distributed uniformly on the PES substrate. The composite membrane with a coating of PDA and CDs (PDA-CD-TFC) exhibited a unique nodule structure with only $30 \mathrm{~nm}$ cross-section thickness, which was one-third and one-sixth of those of pristine TFC and a CD-TFC membrane, respectively. The degree of cross-linking in the PDA-CD-TFC membranes increased and the permeability declination was reduced with the increase of PDA levels, indicating a successful PDA coating. A sequential coating of PDA-CDs was performed not only to protect the substrate from damage but also to improve the membrane structure. The coating process of the PDA-CD-TFC membrane is illustrated in Figure 10.

\section{PES substrate}

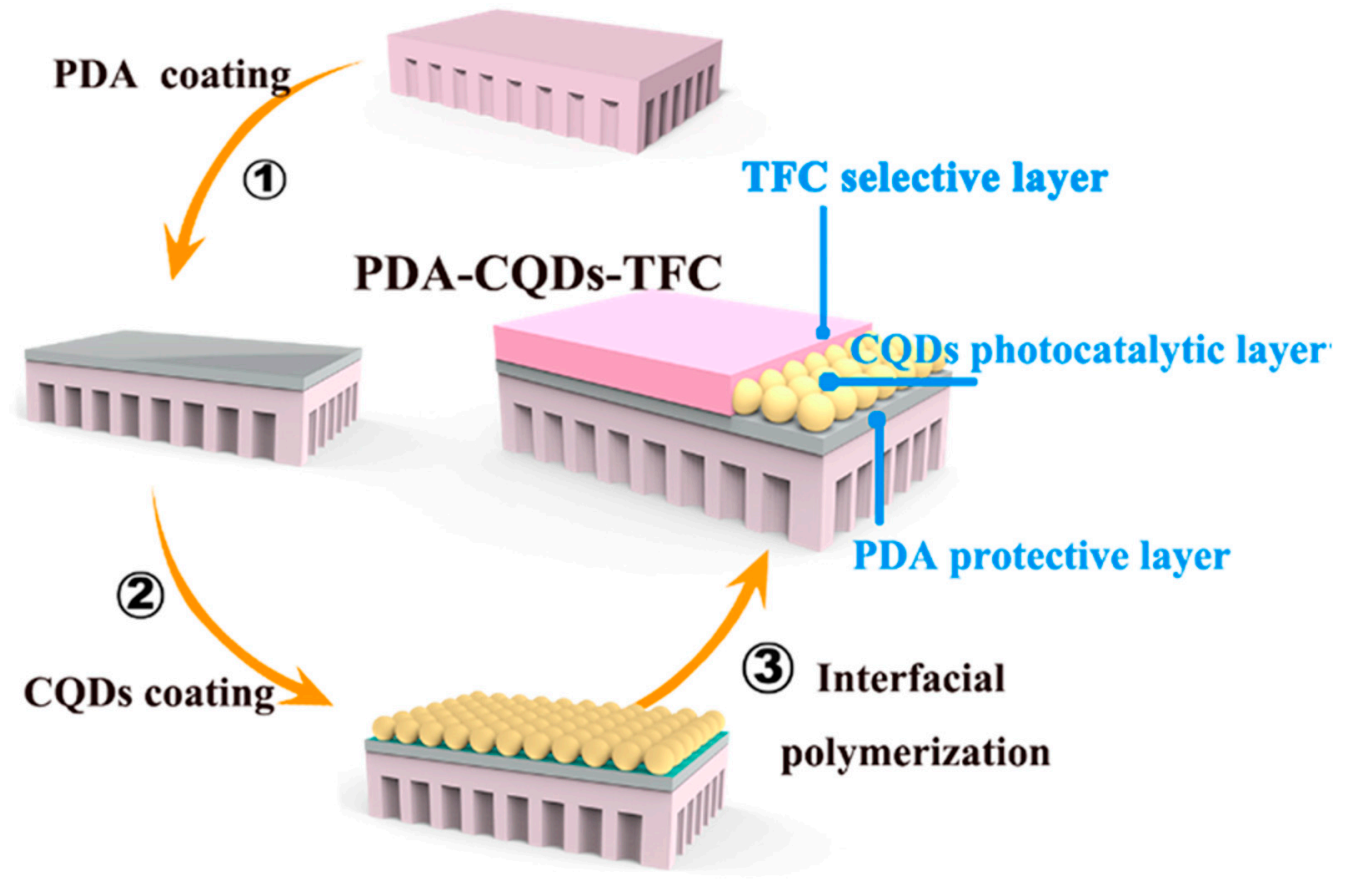

Figure 10. The coating process of a PDA-CD-TFC membrane. Reprinted with permission from [98]. Copyright (2019) American Chemical Society.

\section{Sensing Applications of CD/Polymer Composites}

$\mathrm{CD} /$ polymer composites have been applied for various necessary fields, including sensing applications. $\mathrm{CD} /$ polymer composites have been utilized as chemical sensors for 2,4,6-trinitrophenol (TNP), 4-nitrophenol (4-NP), mesotrione, 2,4-dinitrotoluene (DNT), $\mathrm{Ag}^{+}, \mathrm{Cu}^{2+}$, and $\mathrm{Fe}^{3+}$; as biological sensors for epidermal growth factor receptor (EGFR) epitopes, alkaline phosphatase (ALP), thiabendazole (TBZ), caffeic acid, tetracycline, 3nitrotyrosine (3-NT), and glucose; and as physical sensors for determining temperature and relative humidity. The analytical performance of each composite used as a sensor can be seen in Table 4 . The types of sensing, target analytes, linear ranges, linear coefficients 
$\left(\mathrm{R}^{2}\right)$, and limits of detection (LODs) are summarized. Based on their sensing applications, $\mathrm{CD}$ precursors, $\mathrm{CD}$ synthesis methods, polymer precursors, and $\mathrm{CD} /$ polymer synthesis methods were correlated as shown in Figure 11. Citric acid, some plants (mango peels, acerola fruit, Cedrus, and rosemary leaves), glucose, o-phenylenediamine, cetylpyridinium chloride, and ammonium citrate have been used as CDs precursors. These precursors have been utilized to produce CDs using hydrothermal, solvothermal, microwave, and ultrasonic treatments. The $\mathrm{CDs}$ have then been used to produce $\mathrm{CD} /$ polymer composites by incorporating several polymer precursors, including APTES, acrylamide, polyvinyl alcohol, and some others (poly (tetramethylene glycol), chitosan, methyl acrylate, alginate, styrene, dopamine, polystyrene, and polyethylene terephthalate) into the CDs. These $\mathrm{CD}$ /polymer composites have been obtained using reverse microemulsion polymerization, sol-gel, drop casting, in situ polymerization, bulk polymerization, cross-linking, free radical dispersion polymerization, and polymer-assisted self-assembly. Finally, the composites have been used as chemical, biological, and physical sensors for various important targets. In this section, we overview the sensing applications of $\mathrm{CD} /$ polymer composites according to their sensing categories.

Table 4. Several sensing applications of $\mathrm{CD} /$ polymer composites and their sensing performances.

\begin{tabular}{|c|c|c|c|c|c|c|}
\hline Composites & Applications & Analytes & Linear Range & $\mathbf{R}^{2}$ & LOD & Ref. \\
\hline CDs@MIPs & Chemical Sensor & $4-\mathrm{NP}$ & $0.025-5 \mathrm{mg} / \mathrm{L}$ & 0.9883 & $35 \mathrm{nM}$ & [63] \\
\hline MCOFs@MIPs@CDs & Chemical Sensor & TNP & $0.0003-100 \mu \mathrm{M}$ & 0.9920 & $0.1 \mathrm{nM}$ & [75] \\
\hline TPU/CDs & Chemical Sensor & $\mathrm{Ag}^{+}$ & $0.05-5.0 \mathrm{mM}$ & 0.976 & $12 \mu \mathrm{M}$ & [96] \\
\hline $\mathrm{CDs} / \mathrm{Fe}_{3} \mathrm{O}_{4} @ \mathrm{MIPs}$ & Chemical Sensor & TNP & $1 \mathrm{nM}-100 \mu \mathrm{M}$ & 0.9975 & $0.5 \mathrm{nM}$ & [76] \\
\hline CQDs@MIPs & Chemical Sensor & Mesotrione & $15-3000 \mathrm{nmol} / \mathrm{L}$ & 0.991 & $4.7 \mathrm{nmol} / \mathrm{L}$ & [58] \\
\hline $\mathrm{Y}-\mathrm{CD} / \mathrm{PVA}$ and CS & Chemical Sensor & $\mathrm{Cu}^{2+}$ & $0.0001-0.1 \mathrm{mM}$ & 0.99 & $10 \mathrm{nM}$ & [67] \\
\hline C-dots/PVA & Chemical Sensor & $\mathrm{Fe}^{3+}$ & $\begin{array}{c}0.001-0.012 \\
\mathrm{~mol} / \mathrm{L}\end{array}$ & 0.9925 & $\mathrm{~N} / \mathrm{A}$ & [57] \\
\hline AC-dots-DNT-MIPs & Chemical Sensor & DNT & 1-15 ppm & 0.998 & $0.28 \mathrm{ppm}$ & [83] \\
\hline C-MIP & Biological Sensor & EGFR epitopes & $2.0-15.0 \mu \mathrm{g} / \mathrm{mL}$ & 0.99396 & $0.73 \mu \mathrm{g} / \mathrm{mL}$ & [88] \\
\hline CDs@Cu/Alg & Biological Sensor & ALP & $2-100 \mathrm{mU} / \mathrm{mL}$ & 0.9955 & $0.55 \mathrm{mU} / \mathrm{mL}$ & [68] \\
\hline MIPs-GSCDs & Biological Sensor & Phenobarbital & $0.4-34.5 \mathrm{nmol} / \mathrm{L}$ & 0.997 & $0.1 \mathrm{nmol} / \mathrm{L}$ & [59] \\
\hline CDs@SiO ${ }_{2} @ M I P s$ & Biological Sensor & TBZ & $0.03-1.73 \mu \mathrm{g} / \mathrm{mL}$ & - & $8 \mathrm{ng} / \mathrm{mL}$ & [60] \\
\hline CDs@MIPs & Biological Sensor & Caffeic acid & $0.5-200 \mu \mathrm{M}$ & 0.9973 & $0.11 \mu \mathrm{M}$ & [69] \\
\hline HMIP@CDs & Biological Sensor & Tetracycline & $10-200 \mu \mathrm{g} / \mathrm{L}$ & 0.9972 & $3.1 \mu \mathrm{g} / \mathrm{L}$ & {$[92]$} \\
\hline BMIP@CDs & Biological Sensor & 3-NT & $0.05-1.85 \mu \mathrm{M}$ & 0.9978 & $17 \mathrm{nM}$ & [64] \\
\hline Poly(VPBA-Aam)-CDs & Biological Sensor & Glucose & $0-20 \mathrm{mM}$ & 0.9952 & $\mathrm{~N} / \mathrm{A}$ & [99] \\
\hline WCDs@PS & Physical Sensor & Temp. & $20-80{ }^{\circ} \mathrm{C}$ & 0.979 & $\mathrm{~N} / \mathrm{A}$ & [73] \\
\hline CDs-PET film & Physical Sensor & Humidity & $<55 \%,>55 \%$ & $0.9579,0.9050$ & $\mathrm{~N} / \mathrm{A}$ & [108] \\
\hline
\end{tabular}

CDs/Polymer Composites

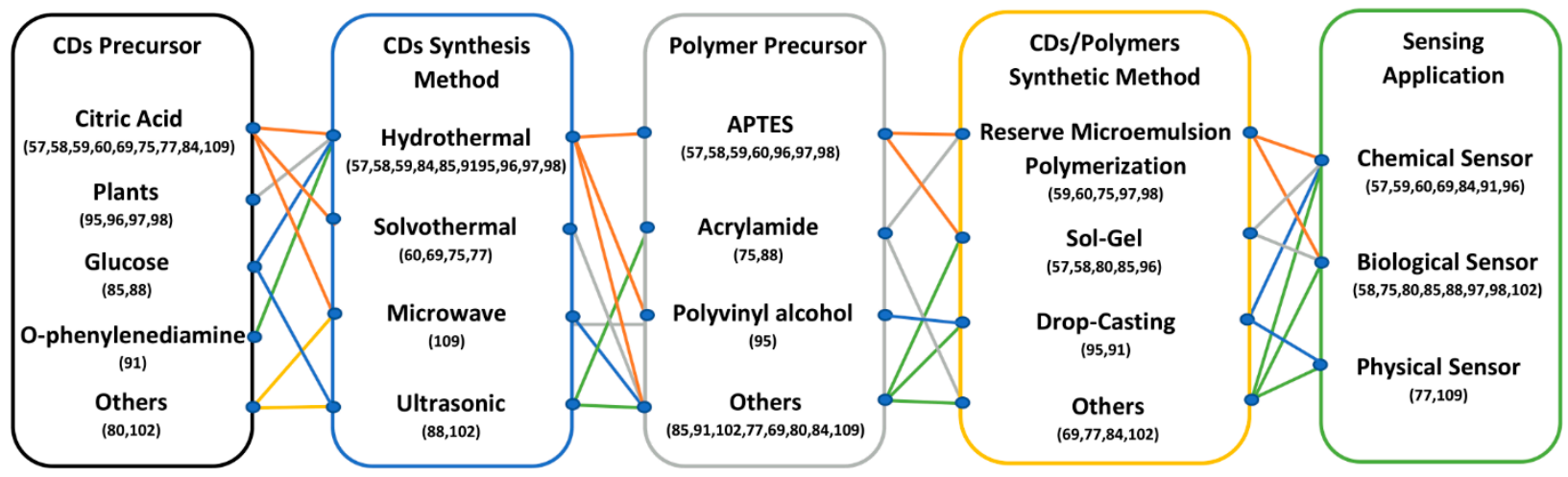

Figure 11. A diagram showing the correlations between the carbon/polymer precursors and synthesis methods of $\mathrm{CD} /$ polymer composites based on their sensing applications. 


\subsection{Chemical Sensors}

Wang et al. applied CDs $/ \mathrm{Fe}_{3} \mathrm{O}_{4} \mathrm{MIPs}$ to assess their selectivity and sensitivity in detecting TNP [76]. TNP is a molecule that reduces the FL intensity of CDs at the excitation and emission wavelengths at $370 \mathrm{~nm}$ and $470 \mathrm{~nm}$, respectively. For selectivity, several competitive compounds of TNP (phenol, 3-nitrophenol, 2-nitrophenol, 4-nitrophenol, mdihydroxybenzene, catechol, pyrogallol, hydroquinone, and 2,4-dinitroaniline) and metal ions $\mathrm{Al}^{3+}, \mathrm{Fe}^{3+}, \mathrm{Fe}^{2+}, \mathrm{Pb}^{2+}, \mathrm{Ba}^{2+}, \mathrm{Cd}^{2+}, \mathrm{Co}^{2+}, \mathrm{Ni}^{2+}$, and $\left.\mathrm{Mg}^{2+}\right)$ were selected to investigate the capability of $\mathrm{CDs} / \mathrm{Fe}_{3} \mathrm{O}_{4} @ \mathrm{MIPs}$ to detect the compounds. The $\mathrm{CDs} / \mathrm{Fe}_{3} \mathrm{O}_{4} @ \mathrm{MIPs}$ exhibited a higher response to TNP than to other species or to CDs/ $/ \mathrm{Fe}_{3} \mathrm{O}_{4} @ \mathrm{NIPs}$. No distinction was observed in the FL intensity of $\mathrm{CDs} / \mathrm{Fe}_{3} \mathrm{O}_{4} @ \mathrm{NIPs}$ among the compounds. These findings indicated that $\mathrm{CDs} / \mathrm{Fe}_{3} \mathrm{O}_{4} @ \mathrm{MIPs}$ have higher adsorption and binding affinity for TNPs due to their special cavities. The CDs $/ \mathrm{Fe}_{3} \mathrm{O}_{4} @ \mathrm{MIPs}$ exhibited high selectivity toward TNP. The FL intensity of $\mathrm{CDs} / \mathrm{Fe}_{3} \mathrm{O}_{4} @ \mathrm{MIPs}$ decreased more than that of CDs $/ \mathrm{Fe}_{3} \mathrm{O}_{4} @ \mathrm{NIPs}$ after adding similar TNP concentrations (Figure 12a,b). This event could be related to the specific imprinted cavities generated by TNP in CDs $/ \mathrm{Fe}_{3} \mathrm{O}_{4} @ \mathrm{MIPs}$ during the synthesis process. Because to the nonspecific TNP adsorption onto the surface of CDs $/ \mathrm{Fe}_{3} \mathrm{O}_{4} @ \mathrm{NIPs}$, TNP can slightly adsorb onto CDs $/ \mathrm{Fe}_{3} \mathrm{O}_{4} @ \mathrm{NIPs}$ with a small FL quenching effect. $\mathrm{CDs} / \mathrm{Fe}_{3} \mathrm{O}_{4} @ \mathrm{MIPs}$ had good linearity in the concentration range of $1 \mathrm{nM}-100 \mu \mathrm{M}$ (Figure 12c). The LOD of CDs $/ \mathrm{Fe}_{3} \mathrm{O}_{4} @ \mathrm{MIPs}$ for TNP was $0.5 \mathrm{nM}$, with an $\mathrm{R}^{2}$ of 0.9975 . Meanwhile, the LOD of CDs $/ \mathrm{Fe}_{3} \mathrm{O}_{4} @ \mathrm{NIPs}$ for TNP was $1 \mu \mathrm{M}$, with an $\mathrm{R}^{2}$ of 0.9920. Therefore, the $\mathrm{CDs} / \mathrm{Fe}_{3} \mathrm{O}_{4} @ \mathrm{MIPs}$ were highly sensitive to TNP. Figure $12 \mathrm{~d}$ shows the data from 0 to $60 \mathrm{~min}$. The adsorption process achieved the equilibrium at $1 \mathrm{~min}$, indicating rapid response time. This method was applied to determine TNP in spiked river and tap water samples with $89.4-108.5 \%$ recoveries and $<6 \%$ RSD.

a

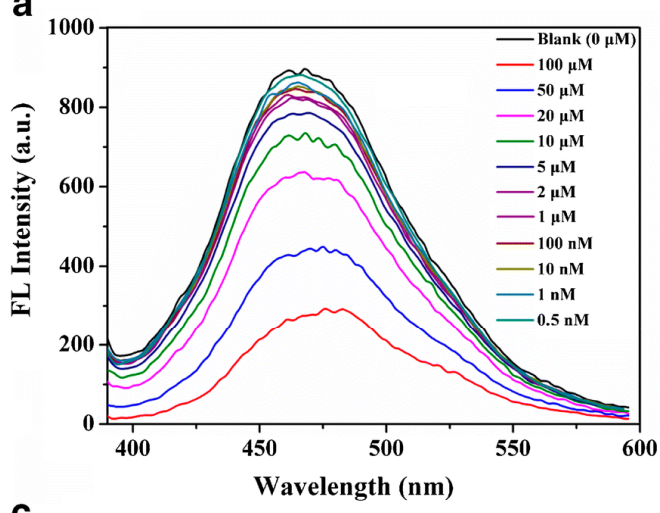

C

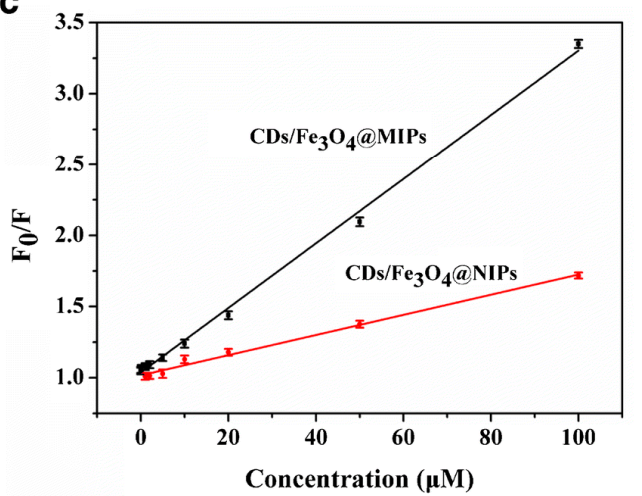

b

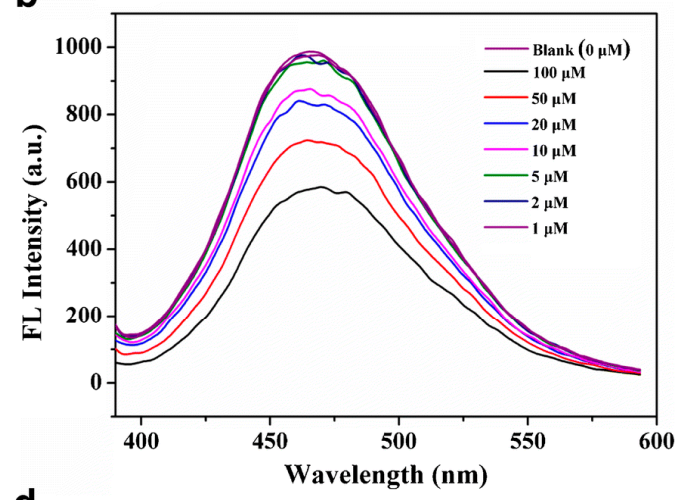

d

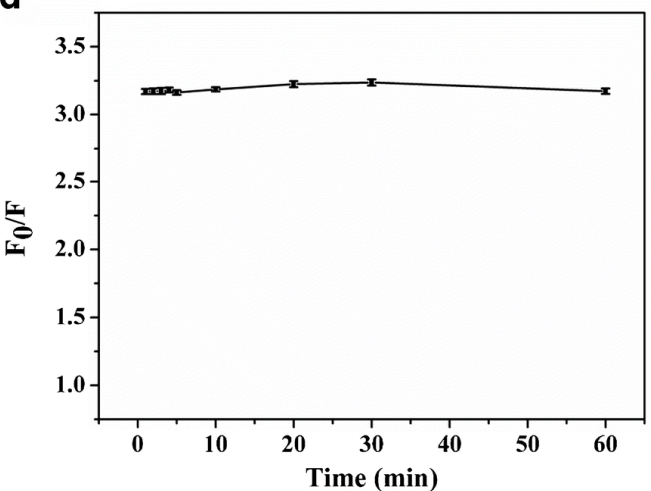

Figure 12. (a) FL emission spectra of $\mathrm{CDs} / \mathrm{Fe}_{3} \mathrm{O}_{4} @ \mathrm{MIPs}$ with TNP concentrations of $0-100 \mu \mathrm{M}$. (b) FL emission spectra of CDs $/ \mathrm{Fe}_{3} \mathrm{O}_{4} @$ NIPs with TNP concentrations of 0-100 $\mu \mathrm{M}$. (c) Calibration curve toward TNP. (d) Dynamic adsorption curve of $\mathrm{CDs} / \mathrm{Fe}_{3} \mathrm{O}_{4} @$ MIPs. Reprinted with permission from [76]. Copyright (2019) Springer-Verlag GmbH Austria, part of Springer Nature. 
Furthermore, Wang et al. applied CDs@MIPs as an FL sensor for sensitive and selective determination of 4-NP [63]. The relative FL intensity of CDs@MIPs reduced gradually as the concentration of 4-NP increased. The LOD of 4-NP was $35 \mathrm{nM}$, with an $\mathrm{R}^{2}$ of 0.9374 . CDs@MIPs could specifically recognize 4-NP among some competitive analogs (phenol, 2-nitrophenol, 3-nitrophenol, pyrogallol, and hydroquinone) and metal ions $\left(\mathrm{Ni}^{2+}, \mathrm{Fe}^{3+}\right.$, $\mathrm{Co}^{2-}, \mathrm{Cd}^{2+}, \mathrm{Pb}^{2+}, \mathrm{Fe}^{2+}$, and $\left.\mathrm{Al}^{3+}\right)$. The decreased impact of this FL sensor may be related to the specific imprinted cavities generated by 4-NP in CDs@MIPs during the preparation process. Then, the CDs@MIPs were effectively utilized to determine 4-NP content in river water samples with $94.0-103.4 \%$ recoveries and $<6.5 \%$ RSD. In addition, Wu et al. applied Y-CDs and Y-CD/polymer composite sensors to determine $\mathrm{Cu}^{2+}$ [67]. Y-CDs showed great selectivity toward $\mathrm{Cu}^{2+}$ over other species $\left(\mathrm{K}^{+}, \mathrm{Mn}^{2+}, \mathrm{Zn}^{2+}, \mathrm{Ba}^{2+}, \mathrm{Cr}^{3+}, \mathrm{Al}^{3+}, \mathrm{Mg}^{2+}, \mathrm{Hg}^{2+}\right.$, $\mathrm{Ca}^{2+}, \mathrm{Pb}^{2+}$, and $\mathrm{Ni}^{2+}$ ) via FL quenching. There was a small alteration in the emission intensity after the addition of various species. The FL intensity reduced linearly $\left(R^{2}=0.99\right)$ with increasing $\mathrm{Cu}^{2+}$ concentration. To improve detection, two Y-CD/polymer composite sensors were prepared: Y-CD/PVA and Y-CD/CS (chitosan). The sensor response of $\mathrm{Y}-\mathrm{CD} / \mathrm{CS}$ was more sensitive than that of Y-CD/PVA films; because of the chelation mechanism of $\mathrm{CS}$ with $\mathrm{Cu}^{2+}, \mathrm{Cu}^{2+}$ can more easily infiltrate into the film. Y-CD/CS films showed good selectivity for $\mathrm{Cu}^{2+}$. When the concentration of $\mathrm{Cu}^{2+}$ increased, the FL of this sensor was reduced dramatically, and the FL color change could be seen by the naked eye. The LOD of Y-CD/CS for $\mathrm{Cu}^{2+}$ was $10 \mathrm{nM}$.

\subsection{Biological Sensors}

Xu et al. applied CDs@MIPs as a sensitive method to detect caffeic acid in human plasma [69]. The CDs@MIPs showed great specificity and binding capability to caffeic acid. The FL intensity of CDs@MIPs lowered gradually as caffeic acid concentration increased from 0.5 to $200 \mu \mathrm{M}$. Figure 13A,B depicts the FL intensity alterations of CDs@MIPs and CDs@NIPs, respectively, as caffeic acid concentration increased. The FL intensity of CDs@MIPs was reduced more than that of CDs@NIPs as caffeic acid concentration increased. The linear relationship between the FL intensity of CDs@MIPs or CDs@NIPs and caffeic acid concentration is shown in Figure 13C. The LODs of CDs@MIPs and CDs@NIPs for caffeic acid were $0.11 \mu \mathrm{M}$ and $0.34 \mu \mathrm{M}$, with $\mathrm{R}^{2}$ of 0.9973 and 0.9936 , respectively. The CDs@MIPs responded to caffeic acid more than CDs@NIPs did. This is related to the specific binding of caffeic acid at certain sites in CDs@MIPs; CDs@NIPs possessed only physical adsorption to caffeic acid. CDs@MIPs could be used at least five times without a notable reduction in their ability to detect caffeic acid (Figure 13D). The FL responses of CDs@MIPs to different interfering substances in plasma, such as $\mathrm{Mg}^{2+}, \mathrm{Ca}^{2+}, \mathrm{Na}^{+}$, galactose, glucose, BSA, Cys, and Gly, were examined. The FL response of CDs@MIPs to caffeic acid was higher than that to the interferents, indicating specific adsorption of CDs@MIPs toward caffeic acid. This method was effectively applied to determine caffeic acid in human plasma, with recoveries in the range of $98.4-107.6 \%$ and RSDs in the range of $3.6-10.2 \%$.

Moreover, Zhang et al. applied C-MIP (CD-incorporated epitope imprinted polymer) to FL imaging of cervical cancer by identifying the EGFR [88]. As C-MIP existed in various concentrations of epitopes solution, C-MIP had nearly no alteration at the emission peak center. However, the FL intensity reduced as the epitopes' concentration increased, exhibiting FL quenching. The FL excitation and emission wavelengths were $540 \mathrm{~nm}$ and $610 \mathrm{~nm}$, respectively. The FL intensity of C-MIP was reduced more than that of C-NIP at identical epitope concentrations. The FL of C-MIP was reduced by the EGFR epitopes because of the inevitable recognition of EGFR epitopes via their imprinted cavities. These imprinted sites, complementary to the template, could specifically identify the target. The linear range of FL quenching was 2.0 to $15.0 \mu \mathrm{g} \mathrm{mL}^{-1}$, and the LOD was $0.73 \mu \mathrm{g} \mathrm{mL}{ }^{-1}$. Therefore, C-MIP could specifically identify the EGFR epitopes. In addition, Jalili and Amjadi applied an FL sensor to detect 3-NT utilizing bioinspired molecularly imprinted polymer (BMIP)@CDs [64]. This sensor was easily produced by dipping CDs 
in a weak alkaline dopamine solution having 3-NT as a template. After extracting the embedded template molecules, the imprinted binding sites were left in the BMIP@CD composite, which was then used to specifically identify 3-NT. For selectivity, several species, such as glucose, sucrose, lactose, ascorbic acid, uric acid, glycine, creatinine, Lcysteine, $\mathrm{K}^{+}, \mathrm{Na}^{+}, \mathrm{Ag}^{+}, \mathrm{NH}_{4}{ }^{+}, \mathrm{Mg}^{2+}, \mathrm{Zn}^{2+}, \mathrm{Ca}^{2+}, \mathrm{Fe}^{2+}, \mathrm{Fe}^{3+}, \mathrm{Pb}^{2+}, \mathrm{Cu}^{2+}, \mathrm{Cd}^{2+}, \mathrm{Ni}^{2+}, \mathrm{Al}^{3+}$, $\mathrm{Cl}^{-}, \mathrm{F}^{-}, \mathrm{SO}_{4}{ }^{2-}, \mathrm{PO}_{4}{ }^{3-}$, and $\mathrm{NO}_{3}{ }^{-}$, were investigated. Only 3-NT had great quenching efficiency on BMIP@CDs. The BMIP@CDs' FL intensity was prominently quenched as 3-NT concentration increased. This sensor had concentration linearity of $0.050-1.85 \mu \mathrm{M}$, with LOD of $17 \mathrm{nM}$ and $\mathrm{R}^{2}$ of 0.9978 . Then, the system was used to detect 3-NT in human serum samples with recoveries in a range of 95.6-101.2\% and RSDs in a range of 1.4-3.9\%.
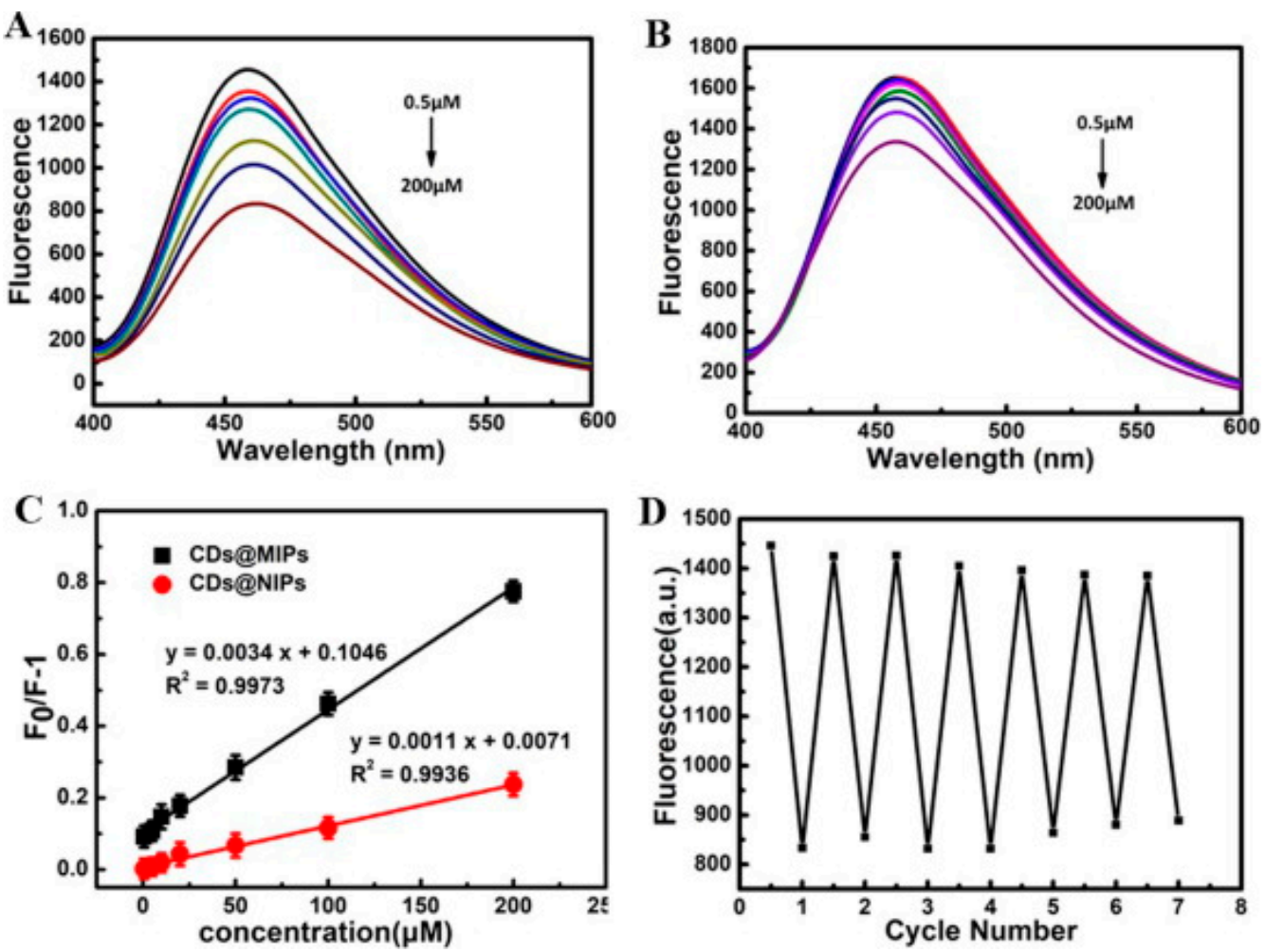

Figure 13. FL emission spectra of (A) CDs@MIPs and (B) CDs@NIPs after adding caffeic acid; (C) the linear correlation between the FL quenching efficiency of CDs@MIPs or CDs@NIPs and caffeic acid concentration; (D) reversible FL quenching and recovery cycles of CDs@MIPs upon the repeated removal (the bottom dots) and addition (the up dots) of caffeic acid. Reprinted with permission from [69]. Copyright (2018) Elsevier.

\subsection{Physical Sensors}

Wang and coworkers implemented WCDs@PS for sensitive detection of temperature [73]. The solid WCDs@PS showed ratiometric FL with temperature-tunable characteristics. As the temperature increased to $80^{\circ} \mathrm{C}$, the FL intensity of BCDs at $430 \mathrm{~nm}$ remained steady. However, the OCD emission at $590 \mathrm{~nm}$ was decreased (Figure 14A,B). The temperature-responsive characteristics of WCDs@PS resulted from OCDs, confirming that PS, as a great linking agent, did not alter the CDs' nature. The intensity ratio of two emission wavelengths $\left(I_{590} / I_{430}\right)$ was analyzed as a temperature function in both backward and forward temperature models. The signal ratio showed good linear correlation with the temperature (Figure 14C). These WLEDs showed a temperature-dependent emission character, the light-emission spectrum of which could be adapted in situ from white $(\lambda \sim 400-730 \mathrm{~nm})$ to blue $(\lambda \sim 440 \mathrm{~nm})$ in the range of $20-80{ }^{\circ} \mathrm{C}$. The FL switching processes were replicated for eight sequent repetitions by several cycles of heating and cooling in the range of $20-80^{\circ} \mathrm{C}$. The finding indicated significant reversibility of the two-way switching operations by WCDs@PS (Figure 14D). Temperature-driven tunable 
LEDs as a thermochromism system would widen the implementation of CD-based lighting systems in specific displays.
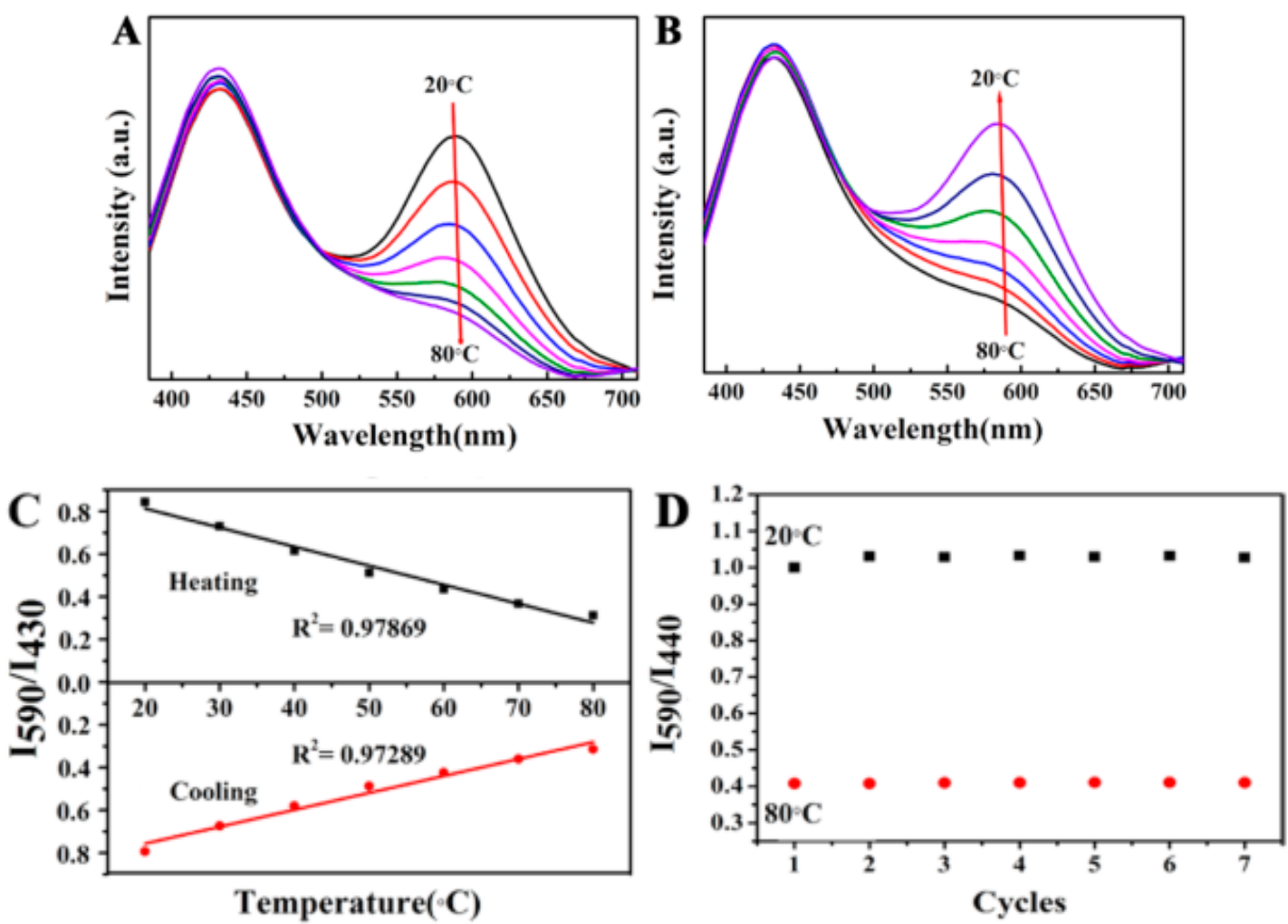

Figure 14. Temperature dependence of WCDs@PS' FL intensity in the solid-state. (A) FL emission spectra excited at $380 \mathrm{~nm}$ as temperature increased from 20 to $80^{\circ} \mathrm{C}$. (B) FL emission spectra excited at $380 \mathrm{~nm}$ as temperature decreased from 80 to $20^{\circ} \mathrm{C}$. (C) Plots of the intensity ratio of $590 / 430 \mathrm{~nm}$ vs. temperature. (D) Eight cycles of intensities were recorded at the temperatures of $20-80^{\circ} \mathrm{C}$. Reprinted with permission from [73]. Copyright (2019) American Chemical Society.

\section{Summary and Future Perspectives}

In this article, the different precursors, preparation methods, optical characteristics, and sensing applications of $\mathrm{CD} /$ polymer composites were overviewed and discussed. $\mathrm{CDs}$ have been produced from numerous carbon precursors, such as inner cassava peels, Acerola fruit, mango peels, Cedrus, rosemary leaf, chitosan, starch, citric acid, glucose, oleic acid, ethanolamine, and some others. Various polymer precursors, including chitosan, cellulose acetate, alginate, APTES, polyethersulfone, polyethyleneimine, polydopamine, polystyrene, polyvinyl alcohol, and some others, were also discussed. CDs have been prepared through various synthesis methods, including hydrothermal, solvothermal, microwave, pyrolysis, and ultrasonic treatments. $\mathrm{CD}$ /polymer composites have been prepared through stirring, sol-gel, drop casting, conventional solution casting, in situ chemical polymerization, reverse microemulsion polymerization, interfacial polymerization, cross-linking reaction, hydrothermal, thermal treatment, photopolymerization, polymer-assisted self-assembly, Schiff base reaction, bulk polymerization, electrospinning, nonsolvent induced phase inversion, and free radical dispersion polymerization. The optical properties and coating characteristics of $\mathrm{CD} /$ polymer composites, including FL properties and UV-vis absorption, were discussed. $\mathrm{CD} /$ polymer composites have shown good performance as chemical, biological, and physical sensors for various targets. The sensing applications of $\mathrm{CD} /$ polymer composites were categorized and discussed. Increasing the sensitivity and selectivity of $\mathrm{CD} /$ polymer composites for various targets would broaden and enrich their sensing capabilities. The obvious advances in $\mathrm{CD} /$ polymer composites for sensing applications make them noteworthy as a prospective material and differentiate them from various carbon 
material composites. Most of the sensing applications of the $\mathrm{CD}$ /polymer composites are dependent on their FL quenching efficiency.

In spite of substantial opportunities afforded by $\mathrm{CD} /$ polymer composites, there are still some challenges in investigating their considerable potential, including: (1) CD/polymer composites can be prepared from various cheap and highly abundant natural carbon and polymer precursors in order to enhance their function; (2) one-step synthesis methods for $\mathrm{CD} /$ polymer composites can be used for efficient and cheap sample preparation; (3) new natural/synthetic precursors for CDs conceiving $\mathrm{N}, \mathrm{S}, \mathrm{P}$, or various heteroatoms could be examined in the future for doped-CD/polymer composites; (4) natural polymer/biopolymer precursors could be considered as green precursors for preparing $\mathrm{CD} /$ polymer composites or other polymer composites; (5) the applications of $\mathrm{CD} /$ polymer composites for various new targets/analytes could be expanded with high sensitivity and selectivity using various sensing methods; and (6) the utilization of $\mathrm{CD} /$ polymer composites as physical sensors was very rare, so increased attention is required in this field. Based on the above perspectives, we hope that the research into $\mathrm{CD} /$ polymer composites can be continued in the future to develop more beneficial aspects in precursors, synthesis methods, characterizations, and applications.

Author Contributions: Conceptualization: G.G.H. and M.Z.; writing—original draft: M.Z.; resources: M.Z., G.G.H. and S.S.; writing-review and editing: M.Z., S.I., A.R., M.A. and G.G.H.; supervision: G.G.H. All authors have read and agreed to the published version of the manuscript.

Funding: This work was financially supported by the Taiwan Ministry of Science and Technology (MOST110-2113-M-037-011) and the Kaohsiung Medical University (KMU-M110008 and KMUHDK(B)110001-4).

Institutional Review Board Statement: Not applicable.

Informed Consent Statement: Not applicable.

Data Availability Statement: Not applicable.

Acknowledgments: The authors thank Kaohsiung Medical University and Universitas Serambi Mekkah for providing resources and other facilities.

Conflicts of Interest: The authors declare no conflict of interest.

\section{References}

1. Xu, X.; Ray, R.; Gu, Y.; Ploehn, H.J.; Gearheart, L.; Raker, K.; Scrivens, W.A. Electrophoretic analysis and purification of fluorescent single-walled carbon nanotube fragments. J. Am. Chem. Soc. 2004, 126, 12736-12737. [CrossRef]

2. Sun, Y.P.; Zhou, B.; Lin, Y.; Wang, W.; Fernando, K.A.S.; Pathak, P.; Meziani, M.J.; Harruff, B.A.; Wang, X.; Wang, H.; et al. Quantum-sized carbon dots for bright and colorful photoluminescence. J. Am. Chem. Soc. 2006, 128, 7756-7757. [CrossRef]

3. Li, H.; He, X.; Kang, Z.; Huang, H.; Liu, Y.; Liu, J.; Lian, S.; Tsang, C.H.A.; Yang, X.; Lee, S.T. Water-soluble fluorescent carbon quantum dots and photocatalyst design. Angew. Chem. Int. Ed. 2010, 49, 4430-4434. [CrossRef]

4. Li, H.; Kang, Z.; Liu, Y.; Lee, S.T. Carbon nanodots: Synthesis, properties and applications. J. Mater. Chem. 2012, 22, $24230-24253$. [CrossRef]

5. Pan, D.; Zhang, J.; Li, Z.; Wu, M. Hydrothermal route for cutting graphene sheets into blue-luminescent graphene quantum dots. Adv. Mater. 2010, 22, 734-738. [CrossRef] [PubMed]

6. Semeniuk, M.; Yi, Z.; Poursorkhabi, V.; Tjong, J.; Jaffer, S.; Lu, Z.H.; Sain, M. Future Perspectives and Review on Organic Carbon Dots in Electronic Applications. ACS Nano 2019, 13, 6224-6255. [CrossRef] [PubMed]

7. Xia, C.; Zhu, S.; Feng, T.; Yang, M.; Yang, B. Evolution and Synthesis of Carbon Dots: From Carbon Dots to Carbonized Polymer Dots. Adv. Sci. 2019, 6, 1901316. [CrossRef]

8. Jia, X.; Li, J.; Wang, E. One-pot green synthesis of optically pH-sensitive carbon dots with upconversion luminescence. Nanoscale 2012, 4, 5572-5575. [CrossRef] [PubMed]

9. Du, X.; Wang, C.; Wu, G.; Chen, S. The Rapid and Large-Scale Production of Carbon Quantum Dots and their Integration with Polymers. Angew. Chem. 2021, 133, 8668-8678. [CrossRef]

10. Miao, X.; Qu, D.; Yang, D.; Nie, B.; Zhao, Y.; Fan, H.; Sun, Z. Synthesis of Carbon Dots with Multiple Color Emission by Controlled Graphitization and Surface Functionalization. Adv. Mater. 2017, 30, 1704740. [CrossRef]

11. Ganguly, S.; Das, P.; Banerjee, S.; Das, N.C. Advancement in science and technology of carbon dot-polymer hybrid composites: A review. Funct. Compos. Struct. 2019, 1, 022001. [CrossRef] 
12. Kausar, A. Polymer/carbon-based quantum dot nanocomposite: Forthcoming materials for technical application. J. Macromol. Sci. Part. A Pure Appl. Chem. 2019, 56, 341-356. [CrossRef]

13. Wang, Y.; Zhu, Y.; Yu, S.; Jiang, C. Fluorescent carbon dots: Rational synthesis, tunable optical properties and analytical applications. RSC Adv. 2017, 7, 40973-40989. [CrossRef]

14. Meng, W.; Bai, X.; Wang, B.; Liu, Z.; Lu, S.; Yang, B. Biomass-Derived Carbon Dots and Their Applications. Energy Environ. Mater. 2019, 2, 172-192. [CrossRef]

15. Zulfajri, M.; Abdelhamid, H.N.; Sudewi, S.; Dayalan, S.; Rasool, A.; Habib, A.; Huang, G.G. Plant Part-Derived Carbon Dots for Biosensing. Biosensors 2020, 10, 68. [CrossRef]

16. Feng, H.; Qian, Z. Functional Carbon Quantum Dots: A Versatile Platform for Chemosensing and Biosensing. Chem. Rec. 2018, 18, 491-505. [CrossRef]

17. Boakye-Yiadom, K.O.; Kesse, S.; Opoku-Damoah, Y.; Filli, M.S.; Aquib, M.; Joelle, M.M.B.; Farooq, M.A.; Mavlyanova, R.; Raza, F.; Bavi, R.; et al. Carbon dots: Applications in bioimaging and theranostics. Int. J. Pharm. 2019, 564, 308-317. [CrossRef]

18. Stepanidenko, E.A.; Ushakova, E.V.; Fedorov, A.V.; Rogach, A.L. Applications of carbon dots in optoelectronics. Nanomaterials 2021, 11, 364. [CrossRef]

19. Wang, X.; Feng, Y.; Dong, P.; Huang, J. A Mini Review on Carbon Quantum Dots: Preparation, Properties, and Electrocatalytic Application. Front. Chem. 2019, 7, 671. [CrossRef]

20. Rasal, A.S.; Yadav, S.; Yadav, A.; Kashale, A.A.; Manjunatha, S.T.; Altaee, A.; Chang, J.-Y. Carbon Quantum Dots for Energy Applications: A Review. ACS Appl. Nano Mater. 2021. [CrossRef]

21. Zhao, B.; Tan, Z. Fluorescent Carbon Dots: Fantastic Electroluminescent Materials for Light-Emitting Diodes. Adv. Sci. 2021, 8, 2001977. [CrossRef] [PubMed]

22. Nair, A.; Haponiuk, J.T.; Thomas, S.; Gopi, S. Natural carbon-based quantum dots and their applications in drug delivery: A review. Biomed. Pharmacother. 2020, 132, 110834. [CrossRef] [PubMed]

23. Jia, Q.; Zhao, Z.; Liang, K.; Nan, F.; Li, Y.; Wang, J.; Ge, J.; Wang, P. Recent advances and prospects of carbon dots in cancer nanotheranostics. Mater. Chem. Front. 2020, 4, 449-471. [CrossRef]

24. Zulfajri, M.; Kao, Y.T.; Huang, G.G. Retrieve of residual waste of carbon dots derived from straw mushroom as a hydrochar for the removal of organic dyes from aqueous solutions. Sustain. Chem. Pharm. 2021, 22, 100469. [CrossRef]

25. Zulfajri, M.; Rasool, A.; Huang, G.G. A fluorescent sensor based on oyster mushroom-carbon dots for sensing nitroarenes in aqueous solutions. New J. Chem. 2020, 44, 10525-10535. [CrossRef]

26. Zulfajri, M.; Liu, K.C.; Pu, Y.H.; Rasool, A.; Dayalan, S.; Huang, G.G. Utilization of carbon dots derived from Volvariella volvacea mushroom for a highly sensitive detection of $\mathrm{Fe}^{3+}$ and $\mathrm{Pb}^{2+}$ ions in aqueous solutions. Chemosensors 2020, 8, 47. [CrossRef]

27. Polatoğlu, B.; Bozkurt, E. Green synthesis of fluorescent carbon dots from Kumquat (Fortunella margarita) for detection of Fe ${ }^{3+}$ ions in aqueous solution. Res. Chem. Intermed. 2021, 47, 1865-1881. [CrossRef]

28. Atchudan, R.; Edison, T.N.J.I.; Perumal, S.; Vinodh, R.; Sundramoorthy, A.K.; Babu, R.S.; Lee, Y.R. Leftover Kiwi Fruit Peel-Derived Carbon Dots as a Highly Selective Fluorescent Sensor for Detection of Ferric Ion. Chemosensors 2021, 9, 166. [CrossRef]

29. Saravanan, A.; Maruthapandi, M.; Das, P.; Luong, J.H.T.; Gedanken, A. Green synthesis of multifunctional carbon dots with antibacterial activities. Nanomaterials 2021, 11, 369. [CrossRef]

30. Liang, Y.; Liu, Y.; Li, S.; Lu, B.; Liu, C.; Yang, H.; Ren, X.; Hou, Y. Hydrothermal growth of nitrogen-rich carbon dots as a precise multifunctional probe for both $\mathrm{Fe}^{3+}$ detection and cellular bio-imaging. Opt. Mater. 2019, 89, 92-99. [CrossRef]

31. Lesani, P.; Ardekani, S.M.; Dehghani, A.; Hassan, M.; Gomes, V.G. Excitation-independent carbon dot probes for exogenous and endogenous $\mathrm{Fe}^{3+}$ sensing in living cells: Fluorescence lifetime and sensing mechanism. Sens. Actuators B Chem. 2019, 285, 145-155. [CrossRef]

32. Chen, X.; Bai, J.; Ma, Y.; Yuan, G.; Mei, J.; Zhang, L.; Ren, L. Multifunctional sensing applications of biocompatible N-doped carbon dots as $\mathrm{pH}$ and $\mathrm{Fe}^{3+}$ sensors. Microchem. J. 2019, 149, 103981. [CrossRef]

33. Feng, Z.; Adolfsson, K.H.; Xu, Y.; Fang, H.; Hakkarainen, M.; Wu, M. Carbon dot/polymer nanocomposites: From green synthesis to energy, environmental and biomedical applications. Sustain. Mater. Technol. 2021, 29, e00304.

34. Paquin, F.; Rivnay, J.; Salleo, A.; Stingelin, N.; Silva, C. Multi-phase semicrystalline microstructures drive exciton dissociation in neat plastic semiconductors. J. Mater. Chem. C 2015, 3, 10715-10722. [CrossRef]

35. Li, H.; Liu, R.; Liu, Y.; Huang, H.; Yu, H.; Ming, H.; Lian, S.; Lee, S.T.; Kang, Z. Carbon quantum dots/Cu ${ }_{2} \mathrm{O}$ composites with protruding nanostructures and their highly efficient (near) infrared photocatalytic behavior. J. Mater. Chem. 2012, 22, 17470-17475. [CrossRef]

36. Bui, T.T.; Park, S.Y. A carbon dot-hemoglobin complex-based biosensor for cholesterol detection. Green Chem. 2016, 18, 4245-4253. [CrossRef]

37. Kausar, A. Advances in Polymer/Fullerene Nanocomposite: A Review on Essential Features and Applications. Polym. Plast. Technol. Eng. 2017, 56, 594-605. [CrossRef]

38. Al-Saleh, M.H.; Sundararaj, U. Review of the mechanical properties of carbon nanofiber/polymer composites. Compos. Part. A Appl. Sci. Manuf. 2011, 42, 2126-2142. [CrossRef]

39. Spitalsky, Z.; Tasis, D.; Papagelis, K.; Galiotis, C. Carbon nanotube-polymer composites: Chemistry, processing, mechanical and electrical properties. Prog. Polym. Sci. 2010, 35, 357-401. [CrossRef]

40. Pinto, A.M.; Magalhães, F.D. Graphene-Polymer Composites. Polymers 2021, 13, 685. [CrossRef] 
41. Zhou, Y.; Sharma, S.K.; Peng, Z.; Leblanc, R.M. Polymers in carbon dots: A review. Polymers 2017, 9, 67. [CrossRef]

42. De, B. Carbon Dots and Their Polymeric Nanocomposites. In Nanomaterials and Polymer Nanocomposites: Raw Materials to Applications; Karak, N., Ed.; Elsevier Inc.: Amsterdam, The Netherlands, 2018; pp. 217-260, ISBN 9780128146163.

43. Konwar, A.; Gogoi, N.; Majumdar, G.; Chowdhury, D. Green chitosan-carbon dots nanocomposite hydrogel film with superior properties. Carbohydr. Polym. 2015, 115, 238-245. [CrossRef] [PubMed]

44. Jiang, K.; Zhang, L.; Lu, J.; Xu, C.; Cai, C.; Lin, H. Triple-Mode Emission of Carbon Dots: Applications for Advanced AntiCounterfeiting. Angew. Chem. Int. Ed. 2016, 55, 7231-7235. [CrossRef]

45. Feng, X.; Zhao, Y.; Jiang, Y.; Miao, M.; Cao, S.; Fang, J. Use of carbon dots to enhance UV-blocking of transparent nanocellulose films. Carbohydr. Polym. 2017, 161, 253-260. [CrossRef] [PubMed]

46. Huang, J.J.; Zhong, Z.F.; Rong, M.Z.; Zhou, X.; Chen, X.D.; Zhang, M.Q. An easy approach of preparing strongly luminescent carbon dots and their polymer based composites for enhancing solar cell efficiency. Carbon N. Y. 2014, 70, 190-198. [CrossRef]

47. Permatasari, F.A.; Irham, M.A.; Bisri, S.Z.; Iskandar, F. Carbon-based quantum dots for supercapacitors: Recent advances and future challenges. Nanomaterials 2021, 11, 91. [CrossRef]

48. Hao, Y.; Gan, Z.; Xu, J.; Wu, X.; Chu, P.K. Poly(ethylene glycol)/carbon quantum dot composite solid films exhibiting intense and tunable blue-red emission. Appl. Surf. Sci. 2014, 311, 490-497. [CrossRef]

49. Chen, B.B.; Liu, M.L.; Huang, C.Z. Carbon dot-based composites for catalytic applications. Green Chem. 2020, $22,4034-4054$. [CrossRef]

50. Shauloff, N.; Bhattacharya, S.; Jelinek, R. Elastic carbon dot/polymer films for fluorescent tensile sensing and mechano-optical tuning. Carbon N. Y. 2019, 152, 363-371. [CrossRef]

51. Sui, B.; Li, Y.; Yang, B. Nanocomposite hydrogels based on carbon dots and polymers. Chin. Chem. Lett. 2020, $31,1443-1447$. [CrossRef]

52. Jani, M.; Arcos-Pareja, J.A.; Ni, M. Engineered Zero-Dimensional Fullerene/Carbon Dots-Polymer Based Nanocomposite Membranes for Wastewater Treatment. Molecules 2020, 25, 4934. [CrossRef] [PubMed]

53. Kováčová, M.; Špitalská, E.; Markovic, Z.; Špitálský, Z. Carbon Quantum Dots As Antibacterial Photosensitizers and Their Polymer Nanocomposite Applications. Part. Part. Syst. Charact. 2020, 37, 1-11. [CrossRef]

54. Zulfajri, M.; Dayalan, S.; Li, W.Y.; Chang, C.J.; Chang, Y.P.; Huang, G.G. Nitrogen-doped carbon dots from averrhoa carambola fruit extract as a fluorescent probe for methyl orange. Sensors 2019, 19, 5008. [CrossRef]

55. Sun, C.; Zhang, Y.; Wang, P.; Yang, Y.; Wang, Y.; Xu, J.; Wang, Y.; Yu, W.W. Synthesis of Nitrogen and Sulfur Co-doped Carbon Dots from Garlic for Selective Detection of $\mathrm{Fe}^{3+}$. Nanoscale Res. Lett. 2016, 11, 110. [CrossRef] [PubMed]

56. Putro, P.A.; Yudasari, N.; Isnaeni; Maddu, A. Spectroscopy study of Polyvinyl alcohol/carbon dots composite films. Walailak J. Sci. Technol. 2021, 18, 9184. [CrossRef]

57. Carvalho, J.; Santos, L.R.; Germino, J.C.; Terezo, A.J.; Moreto, J.A.; Quites, F.J.; Freitas, R.G. Hydrothermal Synthesis to Waterstable Luminescent Carbon Dots from Acerola Fruit for Photoluminescent Composites Preparation and its Application as Sensors. Mater. Res. 2019, 22, e20180920. [CrossRef]

58. Sun, X.; Liu, Y.; Niu, N.; Chen, L. Synthesis of molecularly imprinted fluorescent probe based on biomass-derived carbon quantum dots for detection of mesotrione. Anal. Bioanal. Chem. 2019, 411, 5519-5530. [CrossRef]

59. Shariati, R.; Rezaei, B.; Jamei, H.R.; Ensafi, A.A. Application of coated green source carbon dots with silica molecularly imprinted polymers as a fluorescence probe for selective and sensitive determination of phenobarbital. Talanta 2019, 194, 143-149. [CrossRef]

60. Kazemifard, N.; Ensafi, A.A.; Rezaei, B. Green synthesized carbon dots embedded in silica molecularly imprinted polymers, characterization and application as a rapid and selective fluorimetric sensor for determination of thiabendazole in juices. Food Chem. 2020, 310, 125812. [CrossRef]

61. Safaei, B.; Youssefi, M.; Rezaei, B.; Irannejad, N. Synthesis and Properties of Photoluminescent Carbon Quantum Dot/Polyacrylonitrile Composite Nanofibers. Smart Sci. 2018, 6, 117-124. [CrossRef]

62. Demir, B.; Lemberger, M.M.; Panagiotopoulou, M.; Medina Rangel, P.X.; Timur, S.; Hirsch, T.; Tse Sum Bui, B.; Wegener, J.; Haupt, K. Tracking Hyaluronan: Molecularly Imprinted Polymer Coated Carbon Dots for Cancer Cell Targeting and Imaging. ACS Appl. Mater. Interfaces 2018, 10, 3305-3313. [CrossRef]

63. Wang, M.; Gao, M.; Deng, L.; Kang, X.; Yang, L.; Quan, T.; Xia, Z.; Gao, D. Composite Material Based on Carbon Dots and Molecularly Imprinted Polymers: A Facile Probe for Fluorescent Detection of 4-Nitrophenol. Nano 2020, 15, 2050105. [CrossRef]

64. Jalili, R.; Amjadi, M. Bio-inspired molecularly imprinted polymer-green emitting carbon dot composite for selective and sensitive detection of 3-nitrotyrosine as a biomarker. Sens. Actuators B Chem. 2018, 255, 1072-1078. [CrossRef]

65. Rimal, V.; Shishodia, S.; Srivastava, P.K. Novel synthesis of high-thermal stability carbon dots and nanocomposites from oleic acid as an organic substrate. Appl. Nanosci. 2020, 10, 455-464. [CrossRef]

66. Fernandes, D.; Heslop, K.A.; Kelarakis, A.; Krysmann, M.J.; Estevez, L. In situ generation of carbon dots within a polymer matrix. Polymer 2020, 188, 122159. [CrossRef]

67. Wu, Q.; Wang, X.; Rasaki, S.A.; Thomas, T.; Wang, C.; Zhang, C.; Yang, M. Yellow-emitting carbon-dots-impregnated carboxy methyl cellulose/poly-vinyl-alcohol and chitosan: Stable, freestanding, enhanced-quenching $\mathrm{Cu}^{2+}$-ions sensor. J. Mater. Chem. C 2018, 6, 4508-4515. [CrossRef]

68. Li, Y.; Huang, Z.Z.; Weng, Y.; Tan, H. Pyrophosphate ion-responsive alginate hydrogel as an effective fluorescent sensing platform for alkaline phosphatase detection. Chem. Commun. 2019, 55, 11450-11453. [CrossRef] 
69. Xu, X.; Xu, G.; Wei, F.; Cen, Y.; Shi, M.; Cheng, X.; Chai, Y.; Sohail, M.; Hu, Q. Carbon dots coated with molecularly imprinted polymers: A facile bioprobe for fluorescent determination of caffeic acid. J. Colloid Interface Sci. 2018, 529, 568-574. [CrossRef] [PubMed]

70. Koulivand, H.; Shahbazi, A.; Vatanpour, V.; Rahmandoust, M. Development of carbon dot-modified polyethersulfone membranes for enhancement of nanofiltration, permeation and antifouling performance. Sep. Purif. Technol. 2020, 230, 115895. [CrossRef]

71. Yuan, Z.; Wu, X.; Jiang, Y.; Li, Y.; Huang, J.; Hao, L.; Zhang, J.; Wang, J. Carbon dots-incorporated composite membrane towards enhanced organic solvent nano filtration performance. J. Memb. Sci. 2018, 549, 1-11. [CrossRef]

72. Zhao, D.L.; Das, S.; Chung, T.S. Carbon Quantum Dots Grafted Antifouling Membranes for Osmotic Power Generation via Pressure-Retarded Osmosis Process. Environ. Sci. Technol. 2017, 51, 14016-14023. [CrossRef]

73. Wang, C.; Hu, T.; Chen, Y.; Xu, Y.; Song, Q. Polymer-Assisted Self-Assembly of Multicolor Carbon Dots as Solid-State Phosphors for Fabrication of Warm, High-Quality, and Temperature-Responsive White-Light-Emitting Devices. ACS Appl. Mater. Interfaces 2019, 11, 22332-22338. [CrossRef]

74. Kumar, V.B.; Sahu, A.K.; Mohsin, A.S.M.; Li, X.; Gedanken, A. Refractive-Index Tuning of Highly Fluorescent Carbon Dots. ACS Appl. Mater. Interfaces 2017, 9, 28930-28938. [CrossRef]

75. Wang, M.; Gao, M.; Deng, L.; Kang, X.; Zhang, K.; Fu, Q.; Xia, Z.; Gao, D. A sensitive and selective fluorescent sensor for 2,4,6-trinitrophenol detection based on the composite material of magnetic covalent organic frameworks, molecularly imprinted polymers and carbon dots. Microchem. J. 2020, 154, 104590. [CrossRef]

76. Wang, M.; Fu, Q.; Zhang, K.; Wan, Y.; Wang, L.; Gao, M.; Xia, Z.; Gao, D. A magnetic and carbon dot based molecularly imprinted composite for fluorometric detection of 2,4,6-trinitrophenol. Microchim. Acta 2019, 186, 86. [CrossRef]

77. Gai, W.; Zhao, D.L.; Chung, T.S. Thin film nanocomposite hollow fiber membranes comprising $\mathrm{Na}^{+}$-functionalized carbon quantum dots for brackish water desalination. Water Res. 2019, 154, 54-61. [CrossRef] [PubMed]

78. He, Y.; Zhao, D.L.; Chung, T.S. $\mathrm{Na}^{+}$functionalized carbon quantum dot incorporated thin-film nanocomposite membranes for selenium and arsenic removal. J. Memb. Sci. 2018, 564, 483-491. [CrossRef]

79. Gai, W.; Zhao, D.L.; Chung, T.S. Novel thin film composite hollow fiber membranes incorporated with carbon quantum dots for osmotic power generation. J. Memb. Sci. 2018, 551, 94-102. [CrossRef]

80. Seyedpour, S.F.; Rahimpour, A.; Shamsabadi, A.A.; Soroush, M. Improved performance and antifouling properties of thin-film composite polyamide membranes modified with nano-sized bactericidal graphene quantum dots for forward osmosis. Chem. Eng. Res. Des. 2018, 139, 321-334. [CrossRef]

81. Xu, S.; Li, F.; Su, B.; Hu, M.Z.; Gao, X.; Gao, C. Novel graphene quantum dots (GQDs)-incorporated thin film composite (TFC) membranes for forward osmosis (FO) desalination. Desalination 2019, 451, 219-230. [CrossRef]

82. Sun, $\mathrm{H} . ; \mathrm{Wu}, \mathrm{P}$. Tuning the functional groups of carbon quantum dots in thin film nanocomposite membranes for nanofiltration. J. Memb. Sci. 2018, 564, 394-403. [CrossRef]

83. Dai, J.; Dong, X.; Cortalezzi, M.F. De Molecularly imprinted polymers labeled with amino-functionalized carbon dots for fluorescent determination of 2,4-dinitrotoluene. Microchim. Acta 2017, 184, 1369-1377. [CrossRef]

84. Li, S.; Li, C.; Song, X.; Su, B.; Mandal, B.; Prasad, B.; Gao, X.; Gao, C. Graphene Quantum Dots-Doped Thin Film Nanocomposite Polyimide Membranes with Enhanced Solvent Resistance for Solvent-Resistant Nanofiltration. ACS Appl. Mater. Interfaces 2019, 11, 6527-6540. [CrossRef] [PubMed]

85. Jafari, A.; Kebria, M.R.S.; Rahimpour, A.; Bakeri, G. Graphene quantum dots modified polyvinylidenefluride (PVDF) nanofibrous membranes with enhanced performance for air Gap membrane distillation. Chem. Eng. Process. Process. Intensif. 2018, 126, 222-231. [CrossRef]

86. Bi, R.; Zhang, Q.; Zhang, R.; Su, Y.; Jiang, Z. Thin film nanocomposite membranes incorporated with graphene quantum dots for high flux and antifouling property. J. Memb. Sci. 2018, 553, 17-24. [CrossRef]

87. Bi, R.; Zhang, R.; Shen, J.; Liu, Y.N.; He, M.; You, X.; Su, Y.; Jiang, Z. Graphene quantum dots engineered nanofiltration membrane for ultrafast molecular separation. J. Memb. Sci. 2019, 572, 504-511. [CrossRef]

88. Zhang, Y.; Li, S.; Ma, X.T.; He, X.W.; Li, W.Y.; Zhang, Y.K. Carbon dots-embedded epitope imprinted polymer for targeted fluorescence imaging of cervical cancer via recognition of epidermal growth factor receptor. Microchim. Acta 2020, 187, 187-228. [CrossRef]

89. Hu, T.; Wen, Z.; Thomas, T.; Wang, C.; Song, Q.; Yang, M.; Wang, C. Temperature-controlled spectral tuning of full-color carbon dots and their strongly fluorescent solid-state polymer composites for light-emitting diodes. Nanoscale Adv. 2019, 1, 1413-1420. [CrossRef]

90. Devadas, B.; Imae, T. Effect of Carbon Dots on Conducting Polymers for Energy Storage Applications. ACS Sustain. Chem. Eng. 2018, 6, 127-134. [CrossRef]

91. Tian, Z.; Li, D.; Ushakova, E.V.; Maslov, V.G.; Zhou, D.; Jing, P.; Shen, D.; Qu, S.; Rogach, A.L. Multilevel Data Encryption Using Thermal-Treatment Controlled Room Temperature Phosphorescence of Carbon Dot/Polyvinylalcohol Composites. Adv. Sci. 2018, 5, 1800795. [CrossRef]

92. Li, H.; Zhao, L.; Xu, Y.; Zhou, T.; Liu, H.; Huang, N.; Ding, J.; Li, Y.; Ding, L. Single-hole hollow molecularly imprinted polymer embedded carbon dot for fast detection of tetracycline in honey. Talanta 2018, 185, 542-549. [CrossRef] 
93. Lei, S.; Zeng, M.; Huang, D.; Wang, L.; Zhang, L.; Xi, B.; Ma, W.; Chen, G.; Cheng, Z. Synergistic high-flux oil-saltwater separation and membrane desalination with carbon quantum dots functionalized membrane. ACS Sustain. Chem. Eng. 2019, 7, 13708-13716. [CrossRef]

94. Li, X.; Hu, S.; Lin, Z.; Yi, J.; Liu, X.; Tang, X.; Wu, Q.; Zhang, G. Dual-responsive mesoporous silica nanoparticles coated with carbon dots and polymers for drug encapsulation and delivery. Nanomedicine 2020, 15, 2447-2458. [CrossRef]

95. Kurt, S.B.; Sahiner, N. Chitosan based fibers embedding carbon dots with anti-bacterial and fluorescent properties. Polym. Compos. 2021, 42, 872-880. [CrossRef]

96. Bai, J.; Ren, W.; Wang, Y.; Li, X.; Zhang, C.; Li, Z.; Xie, Z. High-performance thermoplastic polyurethane elastomer/carbon dots bulk nanocomposites with strong luminescence. High. Perform. Polym. 2020, 32, 857-867. [CrossRef]

97. Li, Y.; Li, S.; Zhang, K. Influence of hydrophilic carbon dots on polyamide thin film nanocomposite reverse osmosis membranes. J. Memb. Sci. 2017, 537, 42-53. [CrossRef]

98. Shao, D.-D.; Yang, W.-J.; Xiao, H.-F.; Wang, Z.-Y.; Zhou, C.; Cao, X.-L.; Sun, S.-P. Self-Cleaning Nanofiltration Membranes by Coordinated Regulation of Carbon Quantum Dots and Polydopamine. ACS Appl. Mater. Interfaces 2020, 12, 580-590. [CrossRef] [PubMed]

99. Wang, H.; Yi, J.; Yu, Y.; Zhou, S. NIR upconversion fluorescence glucose sensing and glucose-responsive insulin release of carbon dot-immobilized hybrid microgels at physiological pH. Nanoscale 2017, 9, 509-516. [CrossRef] [PubMed]

100. Yang, W.; Shao, D.; Zhou, Z.; Xia, Q.; Chen, J. Carbon quantum dots (CQDs) nano filtration membranes towards efficient biogas slurry valorization. Chem. Eng. J. 2020, 385, 123993. [CrossRef]

101. Zhao, X.; Wang, A.; Gao, S.; Yan, D.; Guo, W.; Xu, Y.; Meng, Y.; Wang, C.; Shan, G. Enhancing photoluminescence of carbon quantum dots doped PVA films with randomly dispersed silica microspheres. Sci. Rep. 2020, 10, 5710. [CrossRef]

102. Issa, M.A.; Abidin, Z.Z. Sustainable development of enhanced luminescence polymer-carbon dots composite film for rapid Cd ${ }^{2+}$ removal from wastewater. Molecules 2020, 25, 3541. [CrossRef] [PubMed]

103. Bhattacharya, S.; Phatake, R.S.; Barnea, S.N.; Zerby, N.; Zhu, J.; Shikler, R.; Lemcoff, N.G.; Jelinek, R. Fluorescent Self-Healing Carbon Dot/Polymer Gels. ACS Nano 2019, 13, 1433-1442. [CrossRef] [PubMed]

104. Zheng, X.; Ding, G.; Wang, H.; Cui, G.; Zhang, P. One-step hydrothermal synthesis of carbon dots-polymer composites with solid-state photoluminescence. Mater. Lett. 2019, 238, 22-25. [CrossRef]

105. Ma, S.; Zheng, H.; Chen, Y.; Zou, J.; Zhang, C.; Wang, Y. Nanocomposite Polymer Hydrogels Reinforced by Carbon Dots and Hectorite Clay. J. Wuhan Univ. Technol. Mater. Sci. Ed. 2020, 35, 287-292. [CrossRef]

106. Li, S.; Li, C.; Su, B.; Hu, M.Z.; Gao, X.; Gao, C. Amino-functionalized graphene quantum dots (aGQDs)-embedded thin film nanocomposites for solvent resistant nano filtration (SRNF) membranes based on covalence interactions. J. Memb. Sci. 2019, 588, 117212. [CrossRef]

107. Wang, R.; Lu, K.Q.; Tang, Z.R.; Xu, Y.J. Recent progress in carbon quantum dots: Synthesis, properties and applications in photocatalysis. J. Mater. Chem. A 2017, 5, 3717-3734. [CrossRef]

108. Rivadeneyra, A.; Salmeron, J.F.; Murru, F.; Lapresta-Fernández, A.; Rodríguez, N.; Capitan-Vallvey, L.F.; Morales, D.P.; Salinas-Castillo, A. Carbon dots as sensing layer for printed humidity and temperature sensors. Nanomaterials 2020, 10, 2446. [CrossRef]

109. Zulfajri, M.; Gedda, G.; Chang, C.J.; Chang, Y.P.; Huang, G.G. Cranberry Beans Derived Carbon Dots as a Potential Fluorescence Sensor for Selective Detection of $\mathrm{Fe}^{3+}$ Ions in Aqueous Solution. ACS Omega 2019, 4, 15382-15392. [CrossRef]

110. Shi, H.; Wei, J.; Qiang, L.; Chen, X.; Meng, X. Fluorescent carbon dots for bioimaging and biosensing applications. J. Biomed. Nanotechnol. 2014, 10, 2677-2699. [CrossRef]

111. Chan, K.K.; Yap, S.H.K.; Yong, K.T. Biogreen Synthesis of Carbon Dots for Biotechnology and Nanomedicine Applications. Nano-Micro Lett. 2018, 10, 72. [CrossRef]

112. Ghosh, B.; Gogoi, S.; Thakur, S.; Karak, N. Bio-based waterborne polyurethane/carbon dot nanocomposite as a surface coating material. Prog. Org. Coat. 2016, 90, 324-330. [CrossRef]

113. Namdari, P.; Negahdari, B.; Eatemadi, A. Synthesis, properties and biomedical applications of carbon-based quantum dots: An updated review. Biomed. Pharmacother. 2017, 87, 209-222. [CrossRef] [PubMed]

114. Bhattacharya, S.; Sarkar, R.; Chakraborty, B.; Porgador, A.; Jelinek, R. Nitric Oxide Sensing through Azo-Dye Formation on Carbon Dots. ACS Sens. 2017, 2, 1215-1224. [CrossRef] [PubMed]

115. Wang, Y.; Hu, A. Carbon quantum dots: Synthesis, properties and applications. J. Mater. Chem. C 2014, 2, 6921-6939. [CrossRef]

116. Farshbaf, M.; Davaran, S.; Rahimi, F.; Annabi, N.; Salehi, R.; Akbarzadeh, A. Carbon quantum dots: Recent progresses on synthesis, surface modification and applications. Artif. Cells Nanomed. Biotechnol. 2018, 46, 1331-1348. [CrossRef]

117. Zhang, X.; Jiang, M.; Niu, N.; Chen, Z.; Li, S.; Liu, S.; Li, J. Review of Natural-Product-Derived Carbon Dots: From Natural Products to Functional Materials. ChemSusChem 2018, 11, 11-24. [CrossRef]

118. Sharma, A.; Das, J. Small molecules derived carbon dots: Synthesis and applications in sensing, catalysis, imaging, and biomedicine. J. Nanobiotechnol. 2019, 17, 92. [CrossRef]

119. Li, H.; He, X.; Liu, Y.; Huang, H.; Lian, S.; Lee, S.T.; Kang, Z. One-step ultrasonic synthesis of water-soluble carbon nanoparticles with excellent photoluminescent properties. Carbon N. Y. 2011, 49, 605-609. [CrossRef]

120. Kumar, R.; Kumar, V.B.; Gedanken, A. Sonochemical synthesis of carbon dots, mechanism, effect of parameters, and catalytic, energy, biomedical and tissue engineering applications. Ultrason. Sonochem. 2020, 64, 105009. [CrossRef] 
121. Ma, Z.; Ming, H.; Huang, H.; Liu, Y.; Kang, Z. One-step ultrasonic synthesis of fluorescent N-doped carbon dots from glucose and their visible-light sensitive photocatalytic ability. New J. Chem. 2012, 36, 861-864. [CrossRef]

122. Liu, Y.; Wang, P.; Shiral Fernando, K.A.; Lecroy, G.E.; Maimaiti, H.; Harruff-Miller, B.A.; Lewis, W.K.; Bunker, C.E.; Hou, Z.L.; Sun, Y.P. Enhanced fluorescence properties of carbon dots in polymer films. J. Mater. Chem. C 2016, 4, 6967-6974. [CrossRef]

123. Wang, Y.; Zhao, Y.; Zhang, F.; Chen, L.; Yang, Y.; Liu, X. Fluorescent polyvinyl alcohol films based on nitrogen and sulfur co-doped carbon dots towards white light-emitting devices. $N$ J. Chem. 2016, 40, 8710-8716. [CrossRef]

124. Zhang, D.; Wang, Y.; Geng, W.; Liu, H. Rapid detection of tryptamine by optosensor with molecularly imprinted polymers based on carbon dots-embedded covalent-organic frameworks. Sens. Actuators B Chem. 2019, 285, 546-552. [CrossRef]

125. Tian, Z.; Zhang, X.; Li, D.; Zhou, D.; Jing, P.; Shen, D.; Qu, S.; Zboril, R.; Rogach, A.L. Full-Color Inorganic Carbon Dot Phosphors for White-Light-Emitting Diodes. Adv. Opt. Mater. 2017, 5, 1700416. [CrossRef]

126. Zhao, Q.; Song, W.; Zhao, B.; Yang, B. Spectroscopic studies of the optical properties of carbon dots: Recent advances and future prospects. Mater. Chem. Front. 2020, 4, 472-488. [CrossRef]

127. Liu, R.; Wu, D.; Feng, X.; Müllen, K. Bottom-up fabrication of photoluminescent graphene quantum dots with uniform morphology. J. Am. Chem. Soc. 2011, 133, 15221-15223. [CrossRef] [PubMed]

128. Smith, A.M.; Nie, S. Semiconductor nanocrystals: Structure, properties, and band gap engineering. Acc. Chem. Res. 2010, 43, 190-200. [CrossRef]

129. Wu, A.M.; Gambhir, S.S.; Weiss, S. Quantum Dots for Live Cells, in vivo Imaging, and Diagnostics. Science 2016, 307, 538-544.

130. Yang, F.; Zhao, M.; Zheng, B.; Xiao, D.; Wu, L.; Guo, Y. Influence of pH on the fluorescence properties of graphene quantum dots using ozonation pre-oxide hydrothermal synthesis. J. Mater. Chem. 2012, 22, 25471-25479. [CrossRef]

131. Wang, L.; Zhu, S.J.; Wang, H.Y.; Qu, S.N.; Zhang, Y.L.; Zhang, J.H.; Chen, Q.D.; Xu, H.L.; Han, W.; Yang, B.; et al. Common origin of green luminescence in carbon nanodots and graphene quantum dots. ACS Nano 2014, 8, 2541-2547. [CrossRef]

132. Anilkumar, P.; Wang, X.; Cao, L.; Sahu, S.; Liu, J.H.; Wang, P.; Korch, K.; Tackett, K.N.; Parenzan, A.; Sun, Y.P. Toward quantitatively fluorescent carbon-based "quantum" dots. Nanoscale 2011, 3, 2023-2027. [CrossRef] [PubMed]

133. Wang, X.; Cao, L.; Yang, S.-T.; Lu, F.; Meziani, M.J.; Tian, L.; Sun, K.W.; Bloodgood, M.A.; Sun, Y.-P. Bandgap-Like Strong Fluorescence in Functionalized Carbon Nanoparticles. Angew. Chem. 2010, 49, 5310-5314. [CrossRef] [PubMed]

134. De, B.; Karak, N. A green and facile approach for the synthesis of water soluble fluorescent carbon dots from banana juice. RSC Adv. 2013, 3, 8286-8290. [CrossRef]

135. Suzuki, K.; Malfatti, L.; Takahashi, M.; Carboni, D.; Messina, F.; Tokudome, Y.; Takemoto, M.; Innocenzi, P. Design of Carbon Dots Photoluminescence through Organo-Functional Silane Grafting for Solid-State Emitting Devices. Sci. Rep. 2017, 7, 5469. [CrossRef] [PubMed]

136. Hazarika, D.; Karak, N. Biodegradable tough waterborne hyperbranched polyester/carbon dot nanocomposite: Approach towards an eco-friendly material. Green Chem. 2016, 18, 5200-5211. [CrossRef] 